\title{
Two energy suppliers are better than one: survey experiments on consumer engagement with local energy in GB
}

\author{
Nicole E. Watson ${ }^{\mathrm{a}, *}$, Gesche M. Huebner ${ }^{\mathrm{a}}$, Michael J. Fell ${ }^{\mathrm{a}}$, David Shipworth ${ }^{\mathrm{a}}$ \\ ${ }^{a}$ UCL Energy Institute, University College London, 14 Upper Woburn Pl, Bloomsbury, London WC1H ONN
}

\begin{abstract}
Usually consumers have a relationship with a single energy supplier. Increasingly, the option for consumers to retain their current supplier whilst taking on additional contracts with local suppliers is viewed as having the potential to support growth of local renewable energy. This study took a behavioural economic approach and conducted two pre-registered nationally representative survey experiments $(n=1042, n=762)$. The main aims of the study were to assess the attractiveness of a multiple supplier model for British consumers and to understand the role of default effects and associated cognitive biases (loss-aversion, cognitive effort and implied endorsement) in consumers' decisions to remain with incumbent suppliers. Results showed that participants were significantly more likely to engage with local energy suppliers under a multiple supplier model than the current single supplier model. In one experiment, consumers' preference for adding a local supplier under a multiple supplier model was so strong that it overcame default effects. The perception that the supplier has been recommended (i.e. implied endorsement) was the most robust mechanism associated with remaining with default suppliers, suggesting that explicit endorsement of local suppliers may encourage engagement with the energy market. These findings suggest findings suggest that multiple supplier models are likely to be a promising avenue for driving the growth of local energy and opening opportunities for innovation in the British energy market.
\end{abstract}

Highlights

- Two nationally representative survey experiments in Britain showed significantly higher engagement with local energy in a multiple supplier model than a single supplier model

- Implied endorsement of the multiple supplier model had a positive and statistically significant association with engaging with this model

- Offering consumers multiple energy suppliers is likely to be beneficial for driving uptake of local energy suppliers

Keywords: Local energy, behavioural economics, cognitive biases, future energy markets, survey experiment, multiple supplier models

\section{Introduction}

Decentralised energy is increasingly being referenced in UK government strategy documents as having a key role to play in the energy transition (BEIS and Ofgem, 2017; Ofgem, 2017a). Similar trends have been observed internationally (Schmid et al., 2019; van der Schoor and Scholtens, 2015; Zhang et al., 2017). Technologies enabling decentralisation are known as distributed energy resources (DERs): renewable generation and storage units that connect directly to distribution networks (Akorede et al., 2010). The increasing prevalence of DERs is resulting in the emergence of new business models in the energy market. One example is local energy suppliers: "an organisational form with either the legal ability, or in partnership with another agency with that ability, to supply electricity to commercial and domestic consumers predominantly within a single distribution network region or group of regions at the sub-national scale" (Hall and Roelich, 2016, p.287). As well as supporting decarbonisation (Chiradeja and Ramakumar, 2004), effective utilisation of local energy can reduce constraints on the grid at peak times, avoiding expensive infrastructure upgrades (BEIS and Ofgem, 2017). Under some conditions, local energy can even help achieve social policy objectives, such as alleviating fuel

\footnotetext{
* Corresponding author

Email addresses: nicole.watson.17@ucl.ac.uk (Nicole E. Watson), g.huebner@ucl.ac.uk (Gesche M. Huebner), michael.fell@ucl.ac.uk (Michael J. Fell), d.shipworth@ucl.ac.uk (David Shipworth)
} 
poverty, strengthening community ties, and empowering consumers (Wiersma and Devine-Wright, 2014; Gui and MacGill, 2018; Ofgem, 2017a).

However, local energy is also raising challenges for the regulatory frameworks governing the British energy market. Industry codes and regulations revolve around the 'supplier hub' principle: licensed energy suppliers act as an interface between domestic consumers and a centralised energy system, with domestic consumers contracting with one energy supplier at a time (Ofgem, 2018a). This model has been criticised for limiting innovation in the energy market that could benefit consumers, including opportunities for local suppliers (Elexon, 2019; Nolan, 2017; Spence, 2018). Whilst concerns about regulations stifling new market entrants are not new (Littlechild, 2005), Ofgem, the UK energy regulators, are questioning whether the supplier hub model remains fit for purpose in light of increasing decentralisation (Ofgem, 2018a; Nolan, 2017).

One solution is a multiple supplier model (MSM) (Spence, 2018). This is a change to the balance and settlement code that would enable domestic consumers to take on more than one energy supplier. Under this model, households could purchase available electricity from local DER via a local supplier, with their current national-level supplier meeting the rest of their demand. As well as supporting local supplier models, this could also facilitate new business models, such households with solar photovoltaic panels trading energy with neighbours in a peer-to-peer (P2P) system, smart appliances that include the energy used to power them as part of a service, or suppliers dealing exclusively with electric vehicle charging (Spence, 2018).

Many industry stakeholders concur that the current supplier hub model is unlikely to deliver the innovations needed for the energy transition (e.g. Bristol Energy, 2018; DLT, 2018; ELEXON, 2018; Limejump, 2018; Northern Powergrid, 2018; Smartest Energy, 2018). However, views on the value of MSM remain mixed. Some advocate MSM as a means of integrating DER into a centralised grid (e.g. ELEXON, 2018; Gemserv, 2018). Others, particularly larger incumbents, highlight the benefits that have been delivered by the supplier hub model and the challenges and cost of moving away from a model enshrined in industry codes and regulations (e.g. Centrica, 2018; EDF, 2018; E.ON, 2018; ICoSS, 2018; MRA, 2018). Furthermore, consumer advocacy groups, among others, have expressed concerns that the additional complexity introduced by an MSM could risk increasing consumer disengagement, disadvantage disengaged consumers, or lead to a lack of accountability for suppliers in the absence of a single point of contact (Citizens Advice, 2018; Sustainability First, 2018; Octopus Energy, 2018). Given widespread disengagement in the current energy market (Ofgem, 2018b), if changes are to be made to the supplier hub model, it is important to understand how consumers might respond to more complex alternatives.

Despite the relevance of understanding attitudes towards MSMs, this topic has received little attention in the academic literature. This paper draws from a behavioural economic framework to offer the first empirical evidence on consumer preferences regarding MSMs. Specifically, this study aimed to disentangle cognitive biases associated with remaining with incumbent suppliers to understand whether British adults would be more likely to engage with local energy suppliers in an MSM compared to the current single supplier model. Two broadly nationally representative online survey experiments $(n=1042, n=762)$ were conducted in Britain.

\section{Literature review}

\subsection{Future energy markets and consumer attitudes}

A broad and cross-disciplinary literature is beginning to examine how the increasing prevalence of DERs is changing the energy retail market. Strands of this literature range from the role of technologies in enabling business model innovation (Mazur et al., 2019), to sources of value in the energy markets of the future (Wegner et al., 2017; Hall and Foxon, 2014), to the changing role of utility companies (Hannon et al., 2013; Apajalahti et al., 2015; Richter, 2012; Fuentes-Bracamontes, 2016). Whilst there has been work on how alternatives to the supplier hub model might facilitate the rise of local energy supply models (e.g. Hall and Roelich, 2016; Gui and MacGill, 2018), studies in this vein have tended to take a whole-systems perspective or focus on the role of energy utility companies, rather than consumers.

Although there is a large body of literature across Europe and the UK examining consumer attitudes to local energy more broadly (e.g Koirala et al., 2018; Walker et al., 2010; Kalkbrenner and Roosen, 2016; Mundaca et al., 2018; Rogers et al., 2008), MSM have not been explicitly discussed in this literature. Much attention has been devoted to 'community' energy: a subset of local energy characterised by involvement of local stakeholders as investors or volunteers (Walker and Simcock, 2012). Although receiving electricity from a community energy scheme could be supported by an MSM, many of these projects center around a community-driven approach requiring more active citizen participation than switching to or adding on a new local supplier. Regarding local suppliers specifically, a survey $(n=418)$ conducted by consultancy Energy Systems Catapult (2019) found that $58 \%$ of participants expressed positive views about the concept of local energy suppliers, although the study did not ask whether participants would switch to such a service themselves. In Germany, where municipal supply 
models are relatively common, several studies have found evidence of higher willingness to pay for electricity generated locally (Sagebiel et al., 2014; Kalkbrenner et al., 2017). Nonetheless, none of these studies consider alternative energy retail market models such as MSM. Furthermore, given that the German studies recruited from the German population and Sagebiel et al. (2014) used a non-representative convenience sample, these findings are unlikely to generalise to the British market.

The only study in the UK to implicitly address MSM focuses on P2P energy trading rather than local suppliers. Fell et al. (2019) conducted a nationally representative survey experiment to test willingness to participate in $\mathrm{P} 2 \mathrm{P}$ under various conditions, including the proportion of electricity provided by the scheme, implying that the remainder would be provided by another supplier. Stated willingness to participate ranged from $52-66.8 \%$ across conditions. Whilst these results suggest consumers are likely to be open to the idea of receiving electricity from multiple providers, engaging in $\mathrm{P} 2 \mathrm{P}$ differs from switching to a local supplier.

In short, there is a research gap regarding consumer attitudes towards MSMs and how this might affect engagement with local energy suppliers in the UK. In a competitive market, the success of MSMs in supporting local suppliers will largely depend on the willingness of consumers to engage with them. Despite high stated preferences for energy generated from renewable sources (BEIS, 2019) and alternative models such as P2P trading (Fell et al., 2019), current evidence points towards widespread disengagement in the UK energy market. $54 \%$ of consumers remain on default standard variable tariffs (SVTs) - typically the most expensive (Ofgem, 2018b). Furthermore, consumers who do switch tariff are more likely to switch tariff with the same supplier than switch to a new supplier (Ofgem, 2017b). As the energy market becomes increasingly complex, Ofgem have expressed concerns that disengagement might stifle uptake of new suppliers (Ofgem, 2011, 2018a). To gain insight into how consumers sticking with incumbent suppliers might affect uptake of local energy under an MSM, it is important to understand the mechanisms behind this tendency.

\subsection{Behavioural economics and default effects}

One commonly applied model to understand consumer decision making in energy demand is a microeconomic model of utility maximisation and rational choice (Wilson and Dowlatabadi, 2007). Classic economic theory assumes that consumers analyse the costs and benefits of every option and make choices that maximise their utility subject to budget constraints. Accordingly, consumers that could maximise financial gains or other forms of utility by switching energy supplier should do so. For classical economists, consumers' failure to switch to suppliers better aligned with their preferences can be best explained by market failures such as incomplete information, transaction costs and imperfect market competition (Gillingham and Palmer, 2014).

However, a large body of experimental and field evidence suggests that individuals systematically fail to make decisions consistent with a rational choice model of decision making, under circumstances that cannot be explained by market failures (Camerer et al., 2003). For instance, in the field of tariff switching, natural experiments in Germany found that when default electricity tariffs were changed to a 'green' tariff less than $5 \%$ of customers switched back to the previous 'grey' tariff (Pichert and Katsikopoulos, 2008). In these cases, market failures, such as insufficient information about alternatives or the transaction costs of switching could offer a 'rational choice' explanation for the pervasiveness of the default tariff (Gillingham and Palmer, 2014). However, when Pichert and Katsikopoulos (2008) reproduced the scenario in a hypothetical choice experiment, giving participants full information and reducing transaction costs to the click of a button, defaults were still found to have profound effects. These findings have been conceptually replicated several times (Momsen and Stoerk, 2014), including a larger, pre-registered experiment (Vetter and Kutzner, 2016) and a large-scale $(\mathrm{n}=41,952)$ randomised control trial in the field (Ebeling and Lotz, 2015). This suggests that rational choice cannot fully explain decisions to stick with incumbent suppliers.

Behavioural economics offers an alternative explanation. This theory assumes that consumers' failures to make decisions aligned with their preferences are due to 'bounded' rationality: individuals attempt to make rational decisions, but apply mental short-cuts, known as 'cognitive biases' (Simon, 1997). Under this framework, the tendency to remain with incumbents can be conceptualised in terms of 'the default effect'. Defaults refer to "the choice alternative a consumer receives if he/she does not explicitly specify otherwise" (Brown et al., 2004, p.529). Overwhelmingly, experimental and field evidence suggests that defaults 'stick'; that is, people do not tend to move away from the option that is automatically assigned to them (see Johnson and Goldstein, 2003). In the energy context, defaults include tariffs consumers are automatically enrolled on such SVTs, or contracts taken over after moving to a new house.

Under the behavioural economic framework, three mechanisms have been proposed to explain why individuals stick with defaults: cognitive effort; implied endorsement; and loss-aversion (Johnson and Goldstein, 2003; Jachimowicz et al., 2019). Cognitive effort suggests people stick with defaults because of the mental effort required to process alternatives and form preferences (Tversky and Kahneman, 1974; Samuelson and Zeckhauser, 1988; Thaler and Sunstein, 2008). Implied endorsement suggests that individuals stick with defaults because 
they are perceived as recommended to them by the default-setter (McKenzie et al., 2006). For instance, if a supplier switched all its customers to a certain tariff unless they opted-out, this might be perceived as an implicit endorsement of that particular tariff. Loss-aversion suggests individuals perform comparative evaluations against the status quo when making decisions and emphasise potential losses more than potential gains - financial or otherwise (Tversky and Kahneman, 1991). Several studies in Europe and qualitative work from Ofgem point to loss-aversion as a key explanation for consumers remaining with incumbent suppliers (Ek and Söderholm, 2008; Juliusson et al., 2007; Ofgem, 2011). A survey experiment by Nicolson et al. (2017) also found that loss-aversion negatively impacted willingness to switch to a Time-Of-Use tariff in a nationally representative sample of British energy bill payers.

\subsection{Default mechanisms and MSMs}

Whilst there is evidence for each mechanism in isolation, few studies have attempted to disentangle them (c.f. Dinner et al., 2011) and none in the context of energy supplier switching. As evidence suggests that cognitive biases already stifle tariff switching (Ofgem, 2011), it is plausible they would also impact switching to local suppliers. However, it is unclear how an MSM might affect this. For instance, if cognitive effort is the prevailing explanation for consumers' tendency to stick with their current supplier and tariff, the complication of a second supplier may further discourage consumers from engaging with the market. If loss-aversion offers a more convincing explanation, then an MSM might be able to mitigate this, by allowing consumers to 'add on' a local supplier to their current tariff instead of switching entirely. Finally, if implied endorsement can explain consumers' tendency to stay with defaults, this might suggest potential for growing local energy through explicit recommendations. Understanding the mechanisms underlying default effects can therefore provide insight into how MSM might affect uptake of local energy. Specifically, this paper answers the following research questions:

1. Are British adults more likely to engage with a local supplier in a multiple supplier model than under the current single supplier model?

2. To what extent can cognitive effort, implied endorsement and loss-aversion explain default effects in the context of switching to local energy suppliers?

The first experiment in this study focuses on understanding the mechanisms underlying consumers' tendency to stay with defaults. Given the large evidence base attesting to the power of defaults (Johnson and Goldstein, 2003; Jachimowicz et al., 2019), defaults would be expected to have a strong effect on consumer willingness to switch in the context of local energy suppliers.

H1: Individuals will be more likely to choose the supplier presented as the default than the supplier presented as the alternative.

Following behavioural economic theory on the mechanisms driving default effects, three hypotheses can also be derived:

H1a: Higher levels of cognitive effort will be correlated with an decreased likelihood of choosing the option presented as the default.

H1b: Higher perceptions of implied endorsement of the default option will be correlated with an increased likelihood of choosing the option presented as the default.

H1c: Loss-aversion will be correlated with an increased likelihood of choosing the option presented as the default.

The second experiment in the study focuses on understanding whether consumers would be more likely to engage with local energy suppliers in the current single supplier model or an MSM. It also tests the possibility that an MSM might be able to mitigate the effects of loss-aversion associated with switching energy suppliers (Nicolson et al., 2017; Ofgem, 2011), by enabling consumers to 'add on' a local supplier to their current tariff, without having to give anything up.

H2a: Individuals will be more likely to switch to a local energy supplier in an MSM than a single supplier model.

H2b: In a single supplier model, loss-aversion will be correlated with decreased likelihood of switching to a local energy supplier. In a multiple supplier model, there will be no relationship between lossaversion and the likelihood of switching to a local energy supplier. 


\section{Methods and data}

Procedures are reported in accordance with CONSORT guidelines.

\subsection{Participants and procedure}

Two population-based, between-participant survey experiments were conducted to test the hypotheses. Both experiments were delivered online. Online surveys have several advantages over laboratory, telephone or post: they are less resource intensive, allow access to larger samples, and typically have higher response rates (Wright, 2005). As participants are not directly observed, online delivery may also mitigate the risk of Hawthorne effects and social desirability bias. The experiments were delivered in an omnibus survey containing unrelated sections from multiple organisations and participants were recruited topic-blind to avoid self-selection bias of those interested in energy. To mitigate the risk of fatigue effects and priming by previous topics, the experiments were placed in the first position of the omnibus survey.

During the survey design process, individual cognitive interviews were conducted with a small convenience sample with no expertise in the energy field $(n=8)$. Cognitive interviewing is a method of field research which seeks to understand the cognitive processes involved in answering survey questions, in order to detect problems in survey questions and minimise response error (Willis, 2005) After interviewing half of the non-expert sample, a focus group $(n=8)$ was conducted with experts in energy and behaviour at the UCL Energy Institute to further refine questions and treatments. The survey was adapted iteratively, incorporating feedback from both samples.

As Northern Ireland does not share an electricity network with the rest of the UK, the target population was adults in Britain. Market research company Populus was commissioned to recruit a broadly representative sample of 2000 participants from a panel of approximately 165,000 individuals. Inclusion criteria were: 1) aged 18+; 2) living in England, Scotland or Wales. Participants were paid for participating in surveys (£1/5 minutes) and entered into a monthly $£ 250$ prize draw. Quota sampling was used to achieve a nationally representative sample, with quotas set on age, gender, region, and social grade. Although the sample was broadly representative in terms of these demographics, some risks of selection bias remain. Participants must have internet access, excluding approximately $10 \%$ of the population (ONS, 2018). As participants also voluntarily participate in online surveys, certain characteristics may be disproportionately represented.

1200 participants were randomly assigned to the default mechanisms experiment (experiment one) and 800 were assigned to the consumer preferences experiment (experiment two) ${ }^{1}$. Sample sizes were estimated for $95 \%$ power at the $5 \%$ confidence interval, based on effect sizes found in experiments on defaults in tariff switching (Momsen and Stoerk, 2014; Vetter and Kutzner, 2016; Ebeling and Lotz, 2015; Pichert and Katsikopoulos, 2008). As the first experiment tests more hypotheses, a larger sample was required to achieve sufficient statistical power. All randomisation was carried out by Populus.

Before any data were collected, a pre-analysis plan (PAP) was registered online at as.predicted.org. PAPs are increasingly being recognised as an important step to improve transparency in the scientific process (Chambers, 2017; Huebner et al., 2017) and should allow " both the researchers and others to have a higher level of confidence that reported results do not reflect statistical noise hand-picked from the data" (Chuang and Wykstra, 2015, p.2).

\subsection{Treatments}

Treatments are summarised in sections 3.2.1 and 3.2.2. and are reproduced in full in Appendix A.

\subsubsection{Experiment one: Why do consumers stay with defaults?}

The first experiment was designed to understand willingness to engage with local suppliers in an MSM and to untangle cognitive biases associated with remaining with defaults.

Participants were randomly assigned to one of three groups. In all groups, participants were asked to imagine that they receive a letter from their current energy supplier. This letter informed them that their supplier is partnering with a new local energy supplier and offered the opportunity to add on the local energy company's services in an MSM, at no additional cost.

\footnotetext{
${ }^{1}$ After exclusion criteria were applied, $13.5 \%$ of participants in the first experiment were excluded and $11 \%$ of participants in the second, leaving sample sizes of $n=1042$ and $n=762$ respectively. Group allocations are discussed in terms of original planned sample sizes in the methods section, sample sizes used in the analysis are reported in full in the results section.
} 
Figure 1: Diagrammatic representation of research design: experiment one

$\mathrm{N}=1200$

Hypothetical letter from current energy supplier

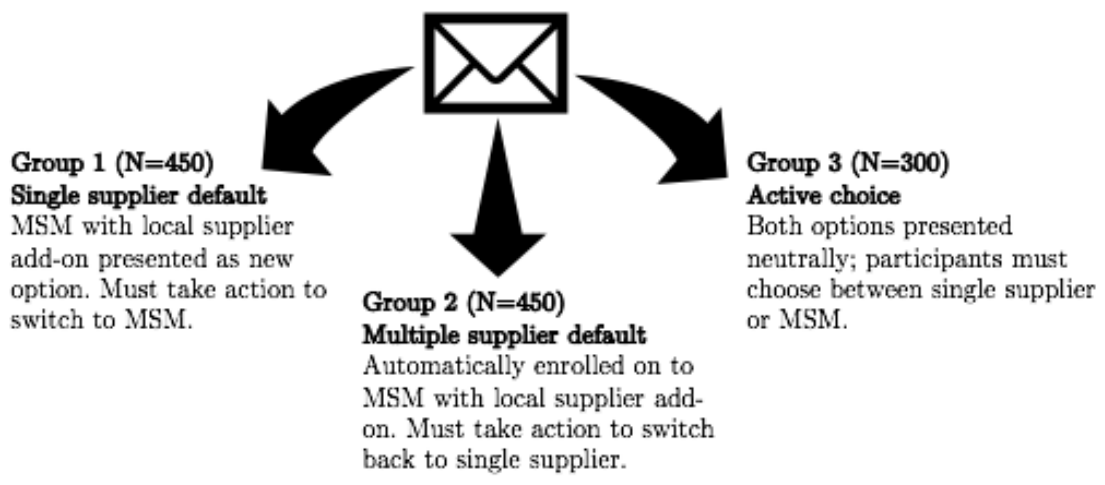

Group one $(n=450)$, the 'single supplier default' group, is equivalent to an opt-in condition. Participants were told that they are currently enrolled on the 'single-provider' model, where all their electricity is provided by their current supplier only. They were offered the opportunity to opt-in to the 'combined-provider' model (effectively an MSM), which would allow them to add on the local energy company's services to their current tariff. Participants were informed that they would have to go online and let their energy supplier know if they would like to switch to the MSM. In the survey, the single supplier model was pre-selected, in order to evoke the transaction costs of switching.

Group two $(\mathrm{n}=450)$, the 'multiple supplier default group' is equivalent to an opt-out condition. Participants were told they had been automatically enrolled on to the new 'combined-provider' model and that they would have to go online and inform their energy supplier if they would like to switch back to the single-provider service. In this condition, the MSM option was pre-selected. Although automatically enrolling customers on to an MSM in partnership with a local supplier is not currently a feasible policy option, this hypothetical scenario allows for testing cognitive biases at work in opt-out defaults.

Group three $(\mathrm{n}=300)$ was an 'active choice' group in order to assess participants' preferences when there is no default. Participants were asked to choose between the two models, which were both presented neutrally, with no pre-selected boxes. As this group was not included in the main analysis, a larger number of participants were allocated to the single and multiple supplier default groups to improve statistical power. The order in which the options were presented was randomised and there was no evidence that the choice order affected the decision made.

\subsubsection{Experiment two: Consumer preferences for supplier models}

The second experiment focuses on whether British adults are more likely to engage with local energy suppliers in an MSM than the current single supplier model and tests the possibility that an MSM might mitigate lossaversion associated with energy supplier switching.

Figure 2: Diagrammatic representation of research design: experiment two

\section{$\mathrm{N}=800$}

Hypothetical letter from new local energy supplier

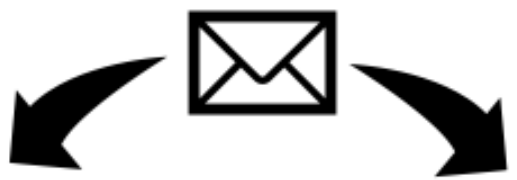

Group one $(\mathrm{N}=400)$

Single supplier condition

Option to switch to new local

energy supplier.
Group two $(\mathrm{N}=400)$

Multiple supplier condition

Option to add on new local energy

supplier to current tariff.

Participants were randomly assigned to one of two conditions. In both groups, participants were asked to 
imagine that they have received a letter from a new local energy supplier advertising their services. Participants were also informed that the options offered would cost the same as their current tariff.

In the 'single supplier' condition $(n=400)$, the local energy company works under the current supplier hub model, buying from the wholesale market when there is not enough locally generated energy to fill their customers' needs. Participants were asked whether they would prefer to remain with their current tariff or switch to the local energy company by going online and informing the local supplier.

In the 'multiple supplier' condition $(n=400)$, the local energy company offers participants the option of adding their services on to their existing contract in an MSM. Participants were asked to choose between staying with their current tariff or adding the local supplier to their current tariff. Again, participants were told that if they wanted to add on the local supplier's services, they could do so by going online and informing the supplier. In both conditions, the option of remaining with the current tariff was pre-selected, to elicit a transaction cost associated with switching.

\subsection{Dependent variable}

The dependent variable (willingness to switch from the default) was measured by participants' answer to the hypothetical scenario they were presented with. Five true/false manipulation checks were included to ensure participants had understood key aspects of the scenario.

\subsection{Independent variables}

Participants also completed a closed-ended, eleven item questionnaire, including measures of each default mechanism. These measures are summarised below and reproduced in full in Appendix B.

\subsubsection{Effort}

The physical effort of switching is controlled for; transaction costs of switching are the same across all conditions that have a default: a click of a button. A measure of cognitive effort was drawn from CooperMartin (1994), who tested several measures and identified five questions with the greatest validity. These questions have also been used by Heidig et al. (2017) to capture differences in an experimental manipulation of cognitive effort.

Cronbach's alpha analysis of self-reported items was conducted (0.79 for experiment one and 0.77 for experiment two). Item five ("I found this decision difficult to make") was dropped due to poor correlation with other items. Treating the five-point Likert scale as continuous (Johnson and Creech, 1983), a mean average of the remaining four items was used to capture cognitive effort ( $1=$ low cognitive effort, $5=$ high cognitive effort). "Don't know" responses were excluded; if a participant answered "don't know" for an individual item, a mean average of remaining items was taken. ${ }^{2}$

The mean average of cognitive effort was $3.64(\mathrm{SE}=0.02)$ in experiment one; $3.78(\mathrm{SE}=0.23)$ in experiment two.

\subsubsection{Implied endorsement}

As implied endorsement is primarily associated with automatic enrollment (McKenzie et al., 2006), this mechanism was only measured in experiment one. Implied endorsement was assessed through a single-item selfreport on a five-point Likert scale (McKenzie et al., 2006; Dinner et al., 2011). As implied endorsement pertains to individuals' perception of the default being endorsed, self-reports are appropriate. To avoid heightening the saliency of implied endorsement, the measure was embedded in a series of other statements about the reasons behind participants' decisions. These were drawn from reasons stated by participants in Pichert and Katsikopoulos (2008)'s laboratory study when asked why they made their choice.

\subsubsection{Loss-aversion}

Loss-aversion was measured by asking participants whether they would accept or reject a series of gambles involving hypothetical losses and gains. These questions derive from standard financial decision problems (Gächter et al., 2010) and were adapted by Nicolson et al. (2017) and Fell et al. (2017) to measure loss-aversion in a representative sample of British energy bill payers. As rational choice theory implies that individuals are risk neutral when it comes to small stakes, the gambles involve small sums of money to avoid evoking risk-aversion,

\footnotetext{
${ }^{2}$ The PAP stated that cognitive effort would be coded by combining participant rankings for the time taken to respond to the question and rankings of the self reports. Correlation between rankings of time taken and rankings of the cognitive effort self reports was statistically significant $(\mathrm{p}<0.01)$, but too weak to be considered consistent $(23 \%$ for experiment one; $12 \%$ for experiment two). For this reason, the measures were not combined and only the self-reported measure of cognitive effort was used in the analysis.
} 
rather than loss-aversion. Gambles $1-4$ are net positive and rejection of any of these gambles was taken to indicate loss-aversion. Rejection of the 50/50 win/lose gamble (5) was not considered to indicate loss-aversion.

Coding of loss-aversion has differed across studies. Gächter et al. (2010) coded loss-aversion according to which specific gambles were rejected. However, this assumes that preferences are linear and that participants would not, for instance, reject gambles involving lower losses and accept gambles involving higher losses. Exploration of the data revealed that approximately $14 \%$ of the sample exhibited inconsistent preferences. Similar inconsistencies were observed by Nicolson et al. (2017), who coded loss-aversion as a dummy variable indicating whether or not an individual showed any loss-aversion. To enable a greater level of nuance, following Fell et al. (2017), lossaversion was coded as a discrete scale indicating the number of net positive gambles rejected $(0=$ no loss-aversion, $4=$ extremely loss-averse).

Across the sample, $8.9 \%$ of participants showed no evidence of loss-aversion: $6.1 \%$ of the sample acted in accordance with classic economic theory, accepting all net positive gambles and rejecting the net negative gamble, and a further $2.8 \%$ accepted all gambles, indicating that they may be risk-positive. $91 \%$ of participants were found to have some level of loss-aversion (i.e. rejected at least one net positive gamble). Levels of lossaversion varied with $35.6 \%$ of the sample being extremely loss-averse (i.e. rejected all gambles). This is similar to the levels of loss-aversion observed by Nicolson et al. (2017) in a representative sample of British energy bill payers.

Figure 3: Annotated distribution of loss-aversion scores

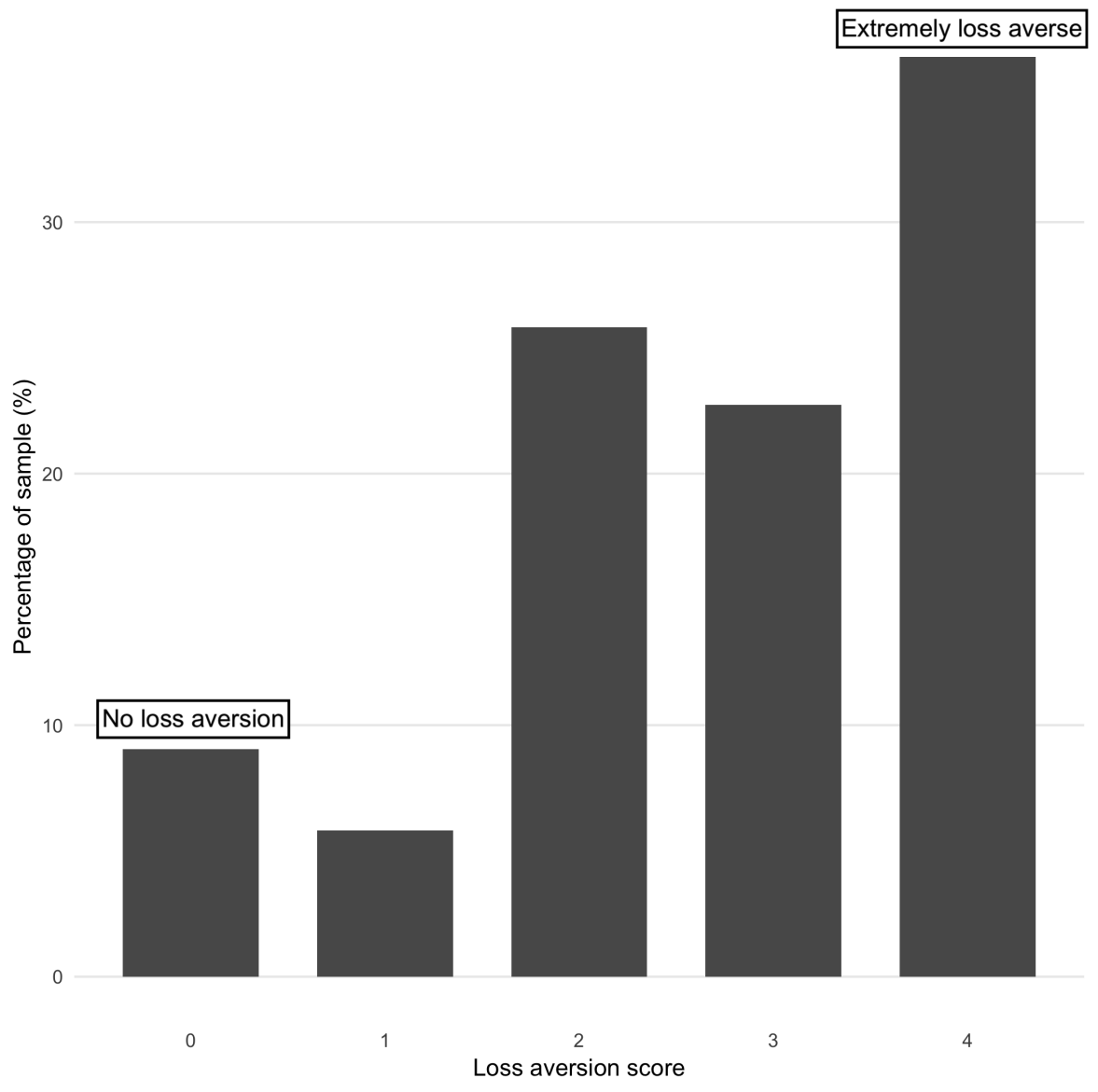

\subsubsection{Covariates}

Data was collected on covariates shown to be associated with cognitive biases or switching energy supplier or tariff. These included demographic variables age, income, tenure, education and gender (Ofgem, 2018b; Rau, 2014) as well as previous energy tariff and supplier switching behaviour, moving house, and satisfaction with current energy supplier (Ek and Söderholm, 2008; Walsh et al., 2005). 


\section{Sample}

As pre-registered, participants who failed more than $50 \%$ of manipulation checks were excluded, as were those who answered "don't know" to all cognitive effort self-reports and to the implied endorsement measure in experiment one. ${ }^{3}$ In total, $13.5 \%$ of participants in experiment one were excluded, $11 \%$ of participants in experiment two. Attrition was evenly balanced between groups.

Figure 4: Participant flow

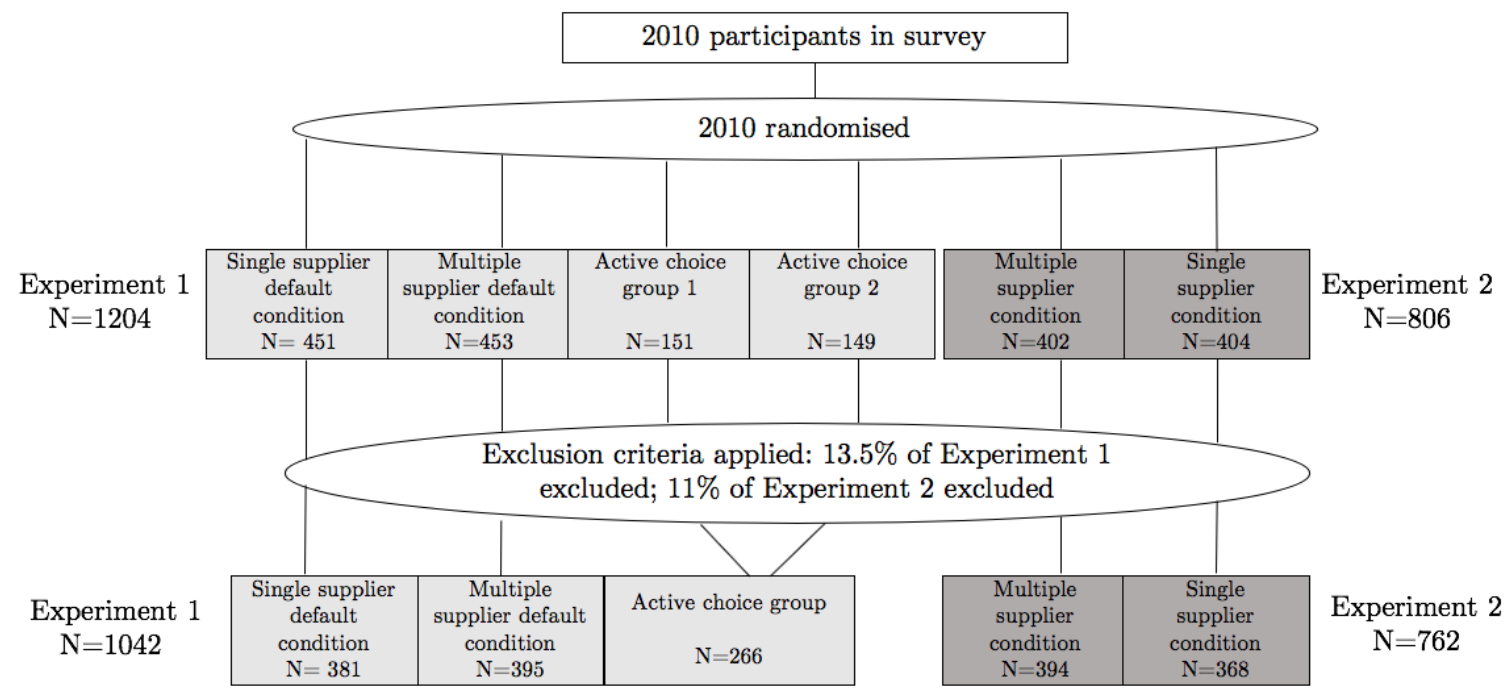

Figure 5 compares the sample to the Office for National Statistics 2018 population estimates for Great Britain (GB), disaggregated by gender and age group (ONS, 2019). Visual analysis shows that there was a slight under-representation of males 25-34. As the sample is otherwise broadly representative of the population of interest with respect to these socio-demographic characteristics, survey weights were not applied. Table 1 presents summary statistics for additional covariates included in the analysis, after the exclusion criteria had been applied.

\footnotetext{
${ }^{3}$ As time taken was no longer used to construct the cognitive effort measure, the pre-specified criteria of excluding participants who took longer than 3 standard deviations above mean average to respond was not applied.
} 


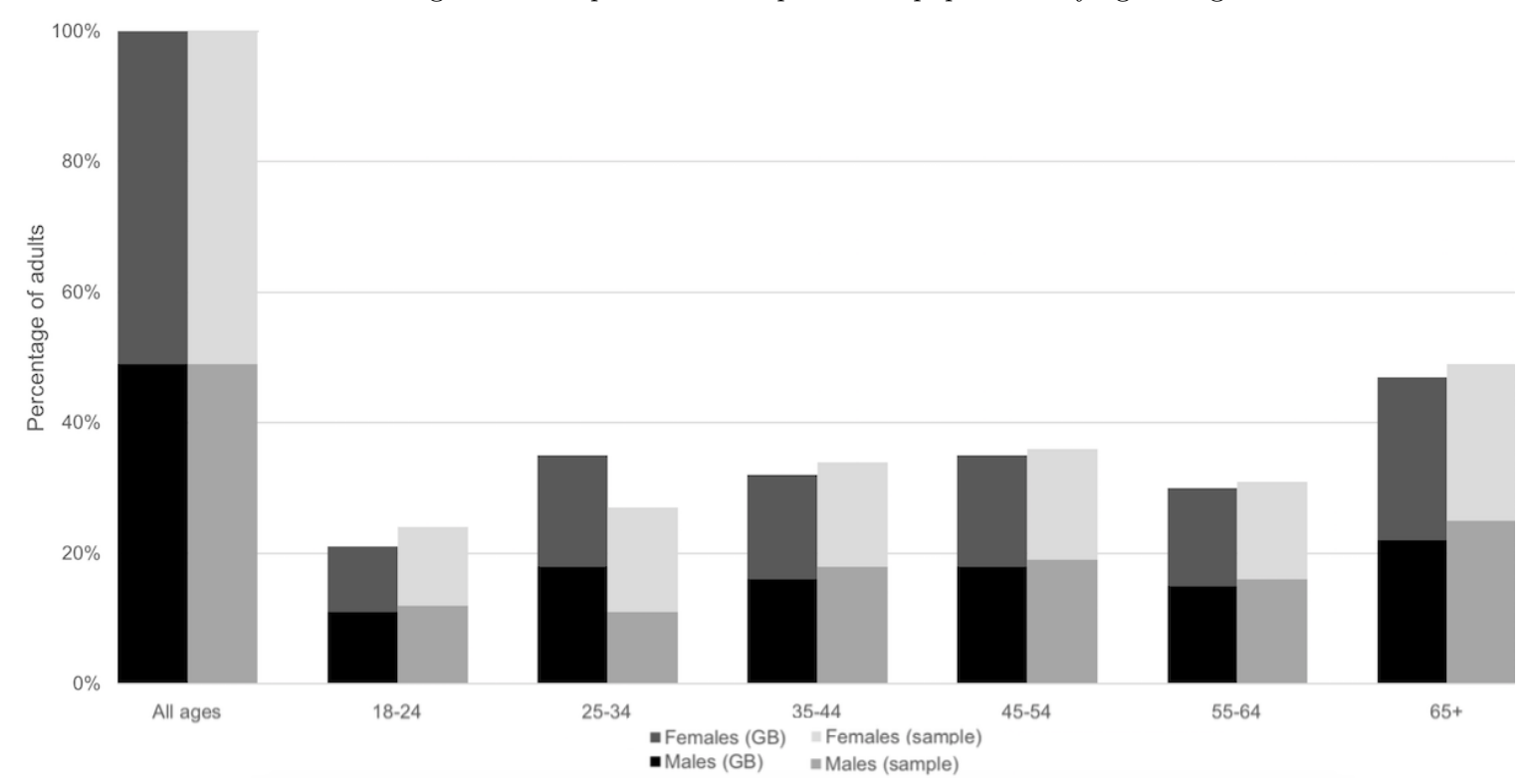

Table 1: Summary of participant characteristics

\begin{tabular}{llc} 
Categorical variables & \multicolumn{2}{c}{ Percentage of sample } \\
& Experiment 1 & Experiment 2 \\
\hline \hline Education & $4 \%$ & $4 \%$ \\
No secondary school education (reference category) & $56 \%$ & $56 \%$ \\
Secondary & $39 \%$ & $39 \%$ \\
Degree or higher & $51 \%$ & $50 \%$ \\
Gender & $49 \%$ & $50 \%$ \\
Female (reference category) & & \\
Male & $61 \%$ & $63 \%$ \\
Tenure & $17 \%$ & $17 \%$ \\
Home-owner (reference category) & $3 \%$ & $2 \%$ \\
Private rent & $19 \%$ & \\
Rent free & & $38 \%$ \\
Social rent & $36 \%$ & $45 \%$ \\
Income & $44 \%$ & $10 \%$ \\
Up to £21,000 (reference category) & $12 \%$ & $91 \%$ \\
£21,001 - £41,000 & & $9 \%$ \\
£41,001 + & $91 \%$ & $38 \%$ \\
Noved house within 12 months & $9 \%$ & $15 \%$ \\
Yes & & $41 \%$ \\
Switched energy tariff or supplier & $41 \%$ & $4 \%$ \\
Never (reference category) & $16 \%$ & $2 \%$ \\
Don't know & $37 \%$ & $50(0.65)$ \\
More than 12 months ago & $5 \%$ & $3.65(0.04)$ \\
Within last 12 months & $1 \%$ & \\
Within last 3 months & & Mean (Standard error) \\
\hline \hline Continuous variables & $49(0.54)$ & \\
\hline \hline Age & $3.74(0.03)$ & \\
Satisfaction with energy supplier & & \\
(1= extremely dissatisfied, 5 extremely satisfied) & & \\
\hline \hline
\end{tabular}




\section{Results}

\subsection{Experiment one: Why do consumers stay with defaults?}

\subsubsection{Supplier model choice}

H1: Individuals will be more likely to choose the energy supplier model presented as the default than the energy supplier model presented as the alternative.

Figure 6: Experiment one: Supplier model chosen by condition

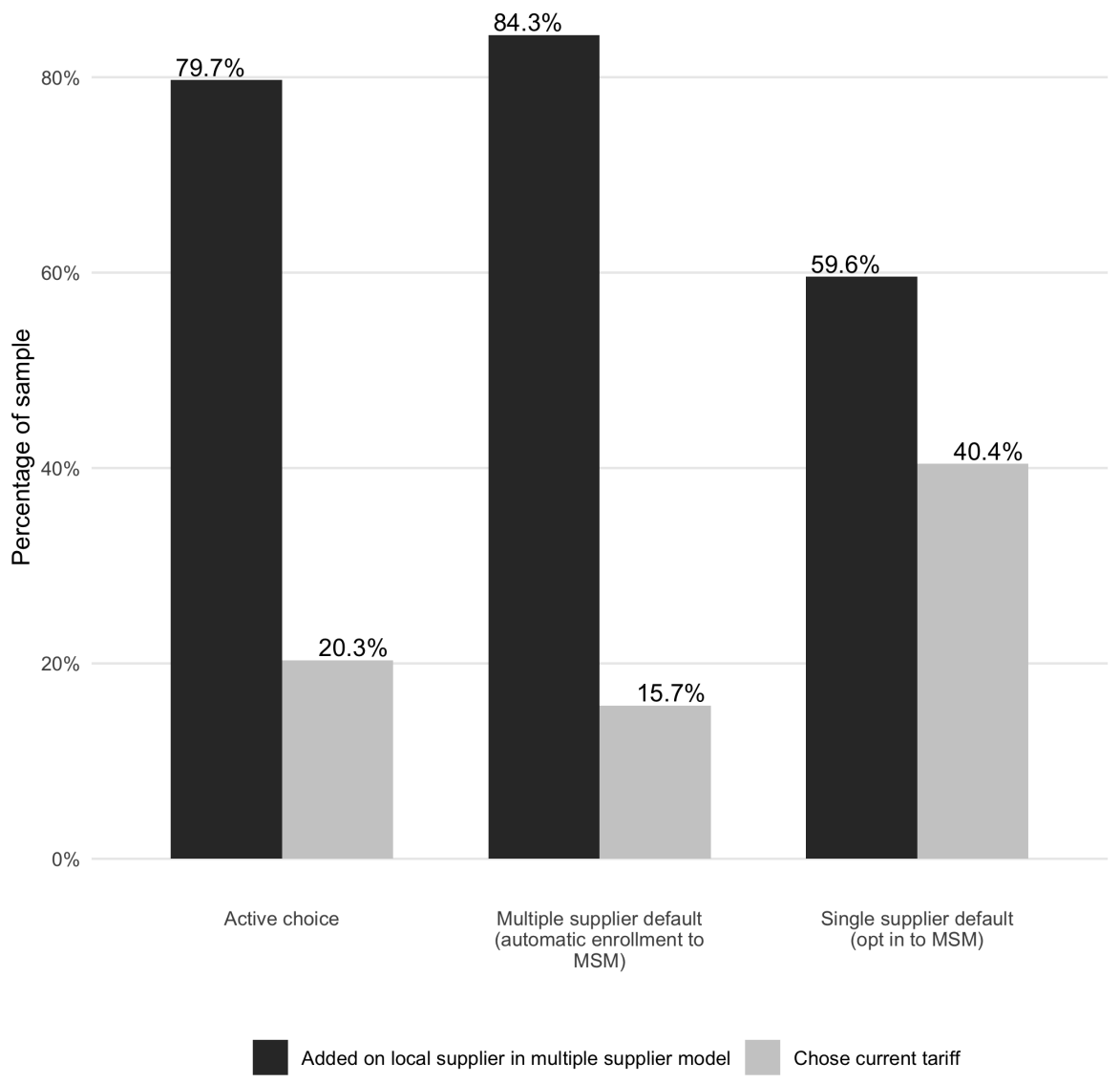

Contrary to expectations, the majority of participants chose to add on a local supplier in an MSM in all conditions, including the single supplier default group. Nonetheless, the proportion of the sample that chose the MSM was greater in the active choice (79.7\%) and multiple supplier default (84.3\%) groups compared to the single supplier default group $(59.6 \%)$.

A 2X3 Chi-squared test showed the overall effect of the condition on participants' choices was large and statistically significant $\left(\chi^{2}=67.6, p<0.01\right)$. Pairwise Chi-squared tests were applied to find out which groups were statistically significantly different from one another. ${ }^{4}$ Only the single supplier default group was found to be statistically significantly different from both the multiple supplier default group $\left(\chi^{2}=57.79, p<0.01\right)$ and the active choice group $\left(\chi^{2}=28.15, p<0.01\right)$. In other words, although the majority of participants in all conditions chose the MSM, participants who had to take action to choose this model were less likely to engage with it. When participants were not given a default option, they were as likely to choose the MSM as those who were automatically enrolled on to it.

Logistic regression models (table 2) also showed that, when holding other covariates constant, participants assigned to the single supplier default group were approximately 8 times more likely to switch to the MSM than those in the multiple supplier default group were to switch back to their current tariff $(p<0.01)$. Overall, these results suggest a strong preference for the MSM and H1 is only supported in the multiple supplier default group.

\footnotetext{
${ }^{4}$ The Bonferroni correction for multiple comparisons was applied in order to reduce the risk of false positives, meaning that a significance level of $=0.016(0.5 / 3)$ was used for the multiple comparisons (Dunn, 1961).
} 


\subsubsection{Default mechanisms}

The next set of analyses reports the effects of each cognitive bias on the likelihood of staying with the assigned default, for the multiple supplier default and single supplier default groups $(n=776)$.

Table 2 presents the results of logistic regression models. Coefficients are presented in odds ratios (OR) with confidence intervals in parentheses. An OR of 1 indicates that there is no association between the predictor and the outcome (switching away from the default: $1=$ switch, $0=$ no switch); an OR $>1$ indicates a positive association; and an $\mathrm{OR}<1$ indicates a negative association. Model 1 includes the treatment effect and all default mechanisms; model 2 includes covariates specified in the PAP; model 3 adds an interaction term between the each default mechanism and treatment group assignment, in order to isolate the effects within each group ${ }^{5}$.

Table 2: Results of logistic regression models - experiment one (default mechanisms)

\begin{tabular}{|c|c|c|c|}
\hline & \multicolumn{3}{|c|}{ Dependent variable: } \\
\hline & \multicolumn{3}{|c|}{ Switching away from default } \\
\hline & $(1)$ & $(2)$ & $(3)$ \\
\hline Single supplier group & $\begin{array}{c}7.795 \\
(5.57-11.038)\end{array}$ & $\begin{array}{c}8.273 \\
(5.789-11.983)\end{array}$ & $\begin{array}{c}4.007 \\
(0.325-54.205)\end{array}$ \\
\hline Cognitive effort & $\begin{array}{c}1.243 \\
(0.981-1.581)\end{array}$ & $\begin{array}{c}1.318 \\
(1.018-1.714)\end{array}$ & $\begin{array}{c}1.760 \\
(1.158-2.748)\end{array}$ \\
\hline Implied endorsement & $\begin{array}{c}0.912 \\
(0.768-1.082)\end{array}$ & $\begin{array}{c}0.947 \\
(0.788-1.138)\end{array}$ & $\begin{array}{c}0.496 \\
(0.358-0.680)\end{array}$ \\
\hline Loss-aversion & $\begin{array}{c}1.038 \\
(0.910-1.185)\end{array}$ & $\begin{array}{c}1.042 \\
(0.900-1.209)\end{array}$ & $\begin{array}{c}1.308 \\
(1.009-1.730)\end{array}$ \\
\hline Single supplier group:cognitive effort & & & $\begin{array}{c}0.654 \\
(0.376-1.118)\end{array}$ \\
\hline Single supplier group: implied endorsement & & & $\begin{array}{c}2.700 \\
(1.833-4.020)\end{array}$ \\
\hline Single supplier group: loss-aversion & & & $\begin{array}{c}0.719 \\
(0.518-0.982)\end{array}$ \\
\hline Controls & & $\checkmark$ & $\checkmark$ \\
\hline Observations & 776 & 714 & 714 \\
\hline Log Likelihood & -426.388 & -385.028 & -368.747 \\
\hline Akaike Inf. Crit. & 862.776 & 810.055 & 783.493 \\
\hline
\end{tabular}

For brevity, odds ratios are only presented for the main independent variables.

See appendix $C$ for full results.

H1a: Increased cognitive effort will mitigate the effect of the default.

Cognitive effort only had a statistically significant effect $(p<0.05)$ in the multiple supplier default group, with an OR of 1.76. In other words, in the multiple supplier default group, those who exercised greater levels of cognitive effort were more likely to take action to switch back to their current tariff. However, in the single supplier default group, cognitive effort had no statistically significant effect. H1a is therefore only supported in the multiple supplier default group.

H1b: Implied endorsement of the default option will be correlated with an increased likelihood of choosing the default option.

In the multiple supplier default group, implied endorsement had a negative and statistically significant effect $(p<0.01)$ with an OR of 0.496: as expected in H1b, the more strongly a participant felt that the option they chose had been endorsed to them, the less likely they were to switch back to the single supplier model. Conversely, in the single supplier default group, implied endorsement was associated with an increased likelihood of choosing the MSM $\left(\mathrm{OR}=0.496^{*} 2.7=1.339, p<0.01\right)$. In other words, in the single supplier group, the more strongly a participant felt that the option they chose was endorsed, the more likely they were to switch to the MSM. H1b is only supported in the multiple supplier default group.

H1c: Loss-aversion will be correlated with an increased likelihood of choosing the default option.

Loss-aversion was significant at the $p<0.05$ level in both groups, in opposite directions. In the single supplier default group, loss-aversion was negatively associated with switching to the MSM, although this effect was very small with an OR of $0.94\left(1.308^{*} 0.719\right)$. For participants in the multiple supplier default group, loss-aversion

\footnotetext{
${ }^{5}$ This analysis was not included in the PAP. However, given the large and statistically significant effect of the treatment group suggests that the effect of the default differed between groups, it seemed likely that the default mechanisms also were also playing a different role in each group.
} 
had a positive and statistically significant association with switching back to the single supplier model, with a moderate OR of 1.308. In other words, the more loss-averse an individual is, the more likely they were to stay with the status quo, even when this involves taking action to switch back. This is in support of H1c.

\subsection{Experiment two: consumer preferences for supplier models}

H2: Participants will be more likely to switch to a local energy supplier in an MSM than in a single supplier model.

In the second experiment, where participants were hypothetically approached by a new local supplier, the majority of participants chose to stay with their current supplier in both the single and multiple supplier model conditions. This is in contrast to the default mechanisms experiment, where the majority chose the MSM regardless of their assigned default. Nonetheless, in the multiple supplier condition, $47.6 \%$ of participants chose to add on the local energy company's services, compared to $37.5 \%$ in the single supplier condition. The treatment effect was statistically significant $(p<0.05)$, with an OR of 1.52. In other words, participants were approximately one and a half times more likely to engage with local energy suppliers in a multiple supplier model than the current single supplier model. This is in support of $\mathrm{H} 2$.

Figure 7: Experiment two: Supplier chosen by condition

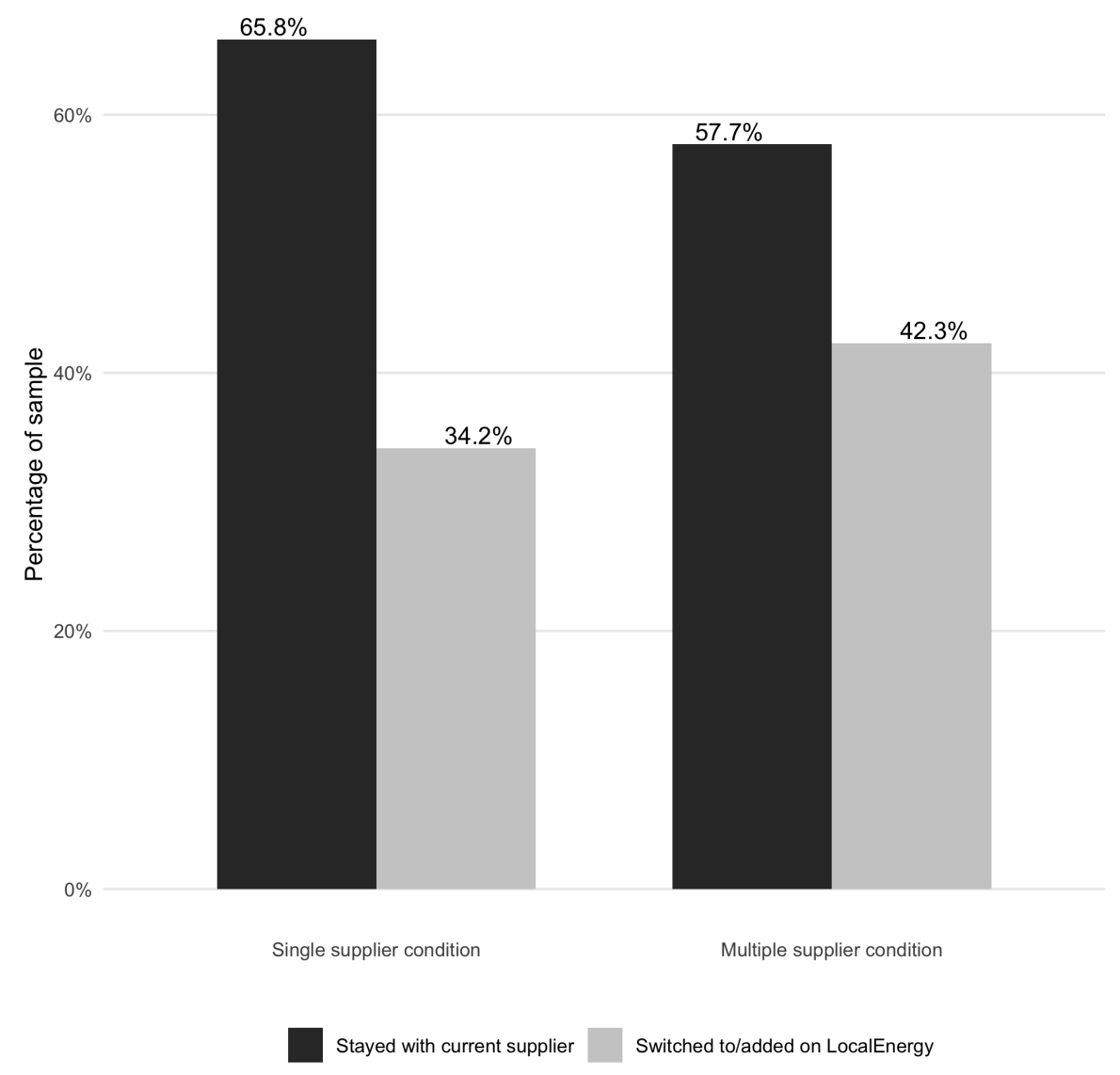

Table 3 presents the results of logistic regression models. Model one represents the effect of the treatment group when controlling for covariates. Model two includes an interaction term between the multiple supplier condition and loss-aversion.

H2a: In a single local supplier model, loss-aversion will be correlated with decreased likelihood of switching to the local supplier. In a multiple supplier model, there will be no relationship between loss-aversion and likelihood of adding on the local supplier.

As expected, loss-aversion did not have a statistically significant effect in the multiple supplier condition. However, there was no effect of loss-aversion on likelihood of switching in the local energy supplier group either. Contrary to expectations, loss-aversion did not appear to play a role in switching to new local suppliers, whether in an MSM or under the current supplier hub model. H2a is therefore not supported. 
Table 3: Results of logistic regression models - experiment two (consumer preferences

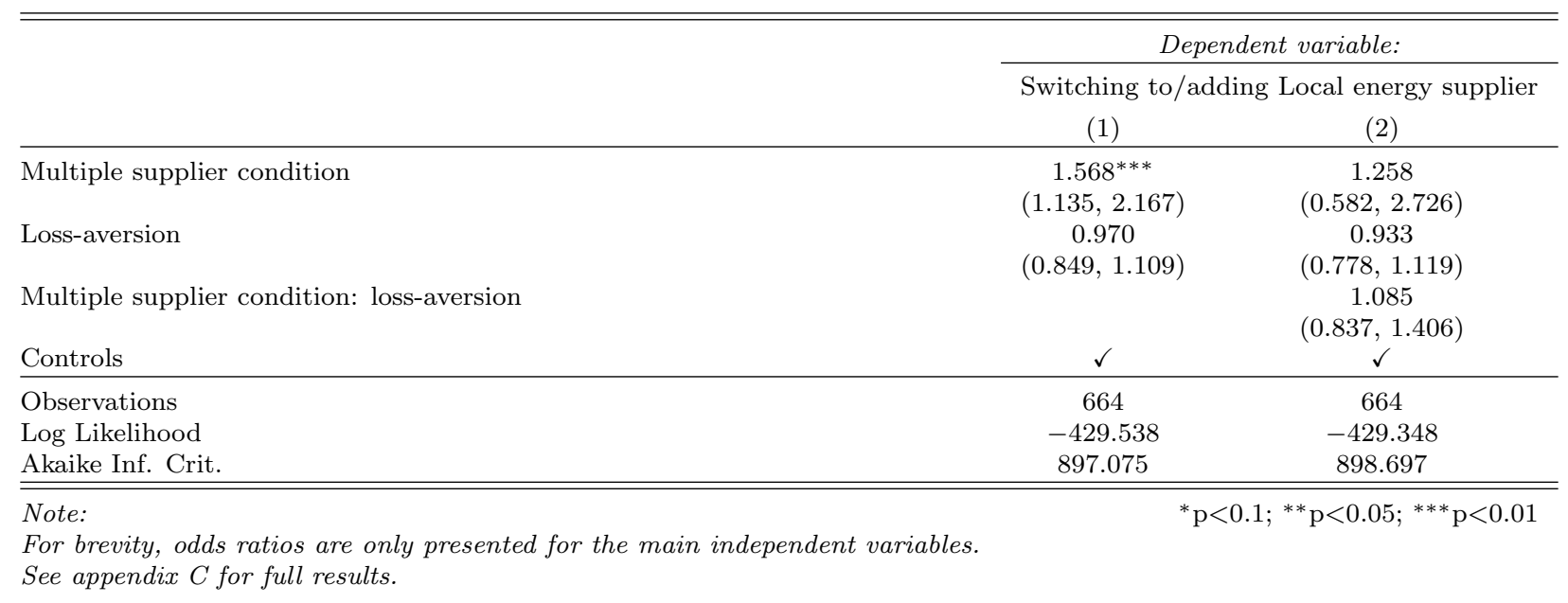

\subsection{Robustness}

Robustness tests were conducted to determine the sensitivity of the results to exclusion criteria and model specification. Results of robustness checks are summarised below and presented in full in Appendix C.

\begin{tabular}{|c|c|c|}
\hline Robustness test & $\begin{array}{l}\text { Experiment one (default mecha- } \\
\text { nisms) }\end{array}$ & $\begin{array}{l}\text { Experiment two (consumer pref- } \\
\text { erences for supplier models) }\end{array}$ \\
\hline $\begin{array}{l}\text { 1. OLS regression models instead of logistic } \\
\text { to test for sensitivity to model specification }\end{array}$ & $\begin{array}{l}\text { Effect of loss-aversion no longer } \\
\text { significant at } P<0.05 \text { level. }\end{array}$ & $\begin{array}{l}\text { Robust (no effect of loss-aversion } \\
\text { in either group) }\end{array}$ \\
\hline $\begin{array}{l}\text { 2. Alternative specification of loss-aversion } \\
\text { as a dichotomous variable }\end{array}$ & $\begin{array}{l}\text { Effect of loss-aversion no longer } \\
\text { significant at } P<0.05 \text { level. } \\
\text { Further analysis found the effect } \\
\text { of loss-aversion to be driven en- } \\
\text { tirely by participants who were } \\
\text { extremely loss averse (rejected all } \\
\text { gambles). }\end{array}$ & $\begin{array}{l}\text { Robust (no effect of loss-aversion } \\
\text { in either group) }\end{array}$ \\
\hline $\begin{array}{l}\text { 3. Benjamini Hochberg correction for multi- } \\
\text { ple hypotheses }\end{array}$ & $\begin{array}{l}\text { The effects of cognitive effort and } \\
\text { loss-aversion both no longer sig- } \\
\text { nificant at } P<0.05 \text { level. Im- } \\
\text { plied endorsement was the only } \\
\text { default mechanism that remained } \\
\text { statistically significant }\end{array}$ & $\mathrm{N} / \mathrm{A}$ \\
\hline $\begin{array}{l}\text { 4. Regional fixed effects to control for poten- } \\
\text { tial omitted variables }\end{array}$ & $\begin{array}{l}\text { Robust: strengthened the effect } \\
\text { and statistical significance of all } \\
\text { findings on default mechanisms }\end{array}$ & Robust \\
\hline 5. No exclusion criteria applied & Robust & Robust \\
\hline
\end{tabular}

With regards to the supplier models chosen and the effect of the treatment groups, the results of both experiments were substantively robust to all alternative specifications tested.

\section{Discussion}

\subsection{Consumer engagement with local energy in an MSM}

The first aim of this study was to understand whether consumers would be willing to engage with local energy suppliers in an MSM. Overall, the results indicate strong interest from consumers in adding a local supplier through a multiple supplier model. The results of the consumer preferences experiment (experiment two) suggest that British adults would be more likely to engage with a local energy supplier in an MSM than under the current single supplier model. More strikingly, the default mechanisms experiment finds that consumers' preference for adding a local supplier under an MSM is so strong that it overrides default effects for all groups this contradicts much of the experimental literature on default effects in energy supplier switching (e.g. Pichert and Katsikopoulos, 2008; Vetter and Kutzner, 2016; Momsen and Stoerk, 2014). This is particularly unexpected, 
given the vast literature on default effects, which overwhelmingly finds that defaults 'stick' (Jachimowicz et al., 2019). Due to the strength of this result, a replication study would be beneficial.

Further field-trial research is also required to test how well stated preferences are likely to translate into consumer behaviour in a commercial environment. The transaction costs of switching are greatly reduced in a hypothetical environment and it may be that participants felt inclined to choose the MSM and local energy option due to perceived social desirability bias. However, this also holds true for studies on switching to 'green' energy suppliers that have found large default effects (e.g. Pichert and Katsikopoulos, 2008; Vetter and Kutzner, 2016; Momsen and Stoerk, 2014). In the MSM context, further research is also needed to understand how additional factors such as price or receiving multiple bills might affect consumer willingness to engage with MSMs. Nonetheless, this study supports a growing body of evidence that consumers are showing an interest in local energy and alternative ways of interacting with the energy market (Fell et al., 2019; Energy Systems Catapult, 2019).

It is, however, worth highlighting that in the second experiment, whilst participants were more likely to switch to a local energy supplier under an MSM than under the current supplier hub model, the majority of participants chose to stay with their current supplier. One key difference between the two experiments was the actor the participant receives the letter from: in the first experiment it is their current energy supplier, in the second it is the new local supplier. Although the experiments were not explicitly designed to test the effect of the actor sending the message, the difference in results suggests consumers' relationships with actors endorsing MSM are also likely to influence willingness to engage with them. Future work could explore questions around trust to understand how consumer relationships might affect willingness to engage with local suppliers in MSMs.

\subsection{Default mechanisms}

The second aim of this study was to understand the mechanisms behind consumers' tendency to stick with defaults. In the default mechanisms experiment, implied endorsement emerged as the most robust mechanism in both groups. In the multiple supplier default group, where participants were automatically enrolled on to the MSM, implied endorsement was associated with an increased likelihood of staying with the MSM default. This supports work by McKenzie et al. (2006), who found experimental evidence that participants view defaults as 'endorsed' by the default-setter, as well as a meta-analysis of default effects, which suggested that defaults are most effective when they work through the implied endorsement mechanism (Jachimowicz et al., 2019). However, in the single supplier default group, the stronger a participant's feeling of implied endorsement for the option they chose, the more likely they were to switch to the MSM. This could suggest that participants perceived the MSM as being endorsed simply by virtue of being the newer option offered in the hypothetical letter.

Cognitive effort only appeared to have an effect in the multiple supplier default group: those who invested more cognitive effort were more likely to switch back to the single supplier model, whereas in the single supplier default group, cognitive effort had no effect on the likelihood of individuals switching to the MSM. One possible explanation for the differing effects of cognitive effort could be the presence of 'rational non-switchers' in the single supplier group: individuals who carefully consider both options and decide that the default is the best option for them. However, there is no reason to expect rational non-switchers only to be present in the single supplier group. It is also possible that there were individuals in the multiple supplier default group who resented automatic enrolment and made a conscious choice to reject this default (Lodge and Wegrich, 2016).

In the default mechanisms experiment (experiment 1), participants who were more loss-averse were more likely to choose the single supplier option, regardless of their default. In other words, loss-aversion was associated with a return to the status quo. This aligns with previous literature on the effect of loss-aversion on supplier switching (Ek and Söderholm, 2008; Nicolson et al., 2017; Juliusson et al., 2007). However, the effect of loss-aversion could not be replicated in the second experiment and was not robust to alternative specifications. This suggests that there are circumstances under which loss-aversion is overcome, which is deserving of further research.

\section{Conclusions and policy implications}

This study set out to understand whether consumers would be more likely to engage with local energy suppliers in a multiple supplier model compared to the current single supplier model and to untangle default mechanisms associated with remaining with incumbent suppliers. The results suggested a strong preference for the MSM; in the first experiment, the majority of participants in all conditions switched to the MSM, even when they had to take action to switch. The second experiment found that participants were statistically significantly more likely to switch to a local energy supplier in an MSM than under the current single supplier model. The most robust finding on default mechanisms was that a greater perception of implied endorsement was associated with an increased likelihood of choosing the MSM in both default conditions. 
Contrary to fears that MSMs would increase consumer disengagement, these findings suggest that MSMs are likely to be a promising avenue for driving the growth of local energy and opening up opportunities for innovation in the British energy market. Furthermore, given the difference in willingness to switch when participants were hypothetically contacted by their current supplier as opposed to a new local supplier, the cooperation and support of existing suppliers is likely to be vital - particularly the 'Big 6', with a 73\% market share (Ofgem, 2019). Whilst all 'Big 6' have expressed concerns about suggestions of dissolving the supplier hub model, many large energy suppliers are engaging with innovative business models that could be enabled by an MSM - for instance Centrica's Local Energy Market in Cornwall and EDF's P2P demonstrator projects (Centrica, n.d.; EDF, n.d.). If MSM are successful, they could allow incumbents to explore new business models whilst avoiding loss of customers.

Regarding consumer engagement, work in the field of energy efficiency home retrofits points to the importance of using trusted actors to engage with consumers and convince them to make a change (Fuller et al., 2010; Rosenow and Porter, 2015); the literature on consumer acceptance of local energy highlights the role of trust in public support for a project (Kalkbrenner and Roosen, 2016; Walker et al., 2010; Koirala et al., 2018); and research on energy supplier switching suggests that rapport with existing suppliers plays an important role for incumbents retaining their customer base (Ek and Söderholm, 2008). Similarly, these finding highlights the importance of engaging trusted figures in promoting MSM. Explicit recommendations of MSMs may also help to drive supplier switching and engagement with innovative offers in the energy market.

\section{Data availability}

The full dataset, survey questions and replication code can be downloaded from: https://github.com/Watson310N/Multiple-suppliers-paper-materials.

The PAP for experiment one is available at: http://aspredicted.org/blind.php? $=\mathrm{x}=\mathrm{b} 8 \mathrm{ba} 4$. The PAP for experiment two is available at: http://aspredicted.org/blind.php? $\mathrm{x}=\mathrm{uq} 98 \mathrm{j} 6$.

\section{Declaration of competing interest}

The authors declare no conflicts of interest.

\section{Funding source}

This research was principally funded by EPSRC grant PETRAS Internet of Things (IoT) Research Hub under the project The Internet of Energy Things ('P2P-IoET'), grant number EP/N02334X/1. Nicole Watson's PhD is funded by the Engineering and Physical Sciences Research Council (EPSRC) Centre for Doctoral Training in Doctoral Training in Energy Demand (LoLo) under Grant number EP/L01517X/1. EPSRC had no involvement in the: study design; collection, analysis and interpretation of data; the writing of the report or; the decision to submit this manuscript for publication.

\section{Author contributions}

Conceptualization, N.W., G.H., M.J.F and D.S.; methodology, N.W., G.H., M.J.F and D.S.; software, N.W; formal analysis, N.W.; investigation, N.W.; data curation, N.W.; writing - original draft preparation, N.W; writing - review and editing, G.H, M.J.F., and D.S.; visualization, N.W; supervision, G.H, M.J.F., and D.S., project administration, N.W.; funding acquisition, D.S.

\section{Acknowledgements}

The following funders are gratefully acknowledged: Engineering and Physical Sciences Research Council (EPSRC) PETRAS IoT Hub. This research was also supported by the EPSRC Centre for Doctoral Training in Doctoral Training in Energy Demand (LoLo), through the first author's doctoral training grant. The authors also thank Dr Moira Nicolson for her helpful feedback on the research design and treatments. 


\section{References}

Akorede, M. F., Hizam, H. and Pouresmaeil, E. (2010), 'Distributed energy resources and benefits to the environment', Renewable and Sustainable Energy Reviews 14(2), 724-734.

URL: http://www.sciencedirect.com/science/article/pii/S1364032109002561

Apajalahti, E.-L., Lovio, R. and Heiskanen, E. (2015), 'From demand side management (DSM) to energy efficiency services: A Finnish case study', Energy Policy 81, 76-85.

URL: http://www.sciencedirect.com/science/article/pii/S0301421515000762

BEIS (2019), BEIS Public Attitudes tracker: Wave 31, Technical report, Department of Business, Energy and Industrial Strategy, London.

URL: https://www.gov.uk/government/statistics/beis-public-attitudes-tracker-wave-31

BEIS and Ofgem (2017), Upgrading our energy system: Smart systems and flexibility plan, Technical report, Department of Business, Energy and Industrial Strategy and Office for Gas and Electricity Markets, London. URL: $\quad$ https://www.gov.uk/government/publications/upgrading-our-energy-system-smart-systems-andflexibility-plan

Bristol Energy (2018), Bristol Energy Response - Future supply market arrangements - response to call for evidence, Technical report.

URL: https://www.ofgem.gov.uk/publications-and-updates/future-supply-market-arrangements-response-ourcall-evidence

Brown, C. L., Krishna, A. and served as associate editor for this article.], D. I. s. a. e. a. S. N. (2004), 'The Skeptical Shopper: A Metacognitive Account for the Effects of Default Options on Choice', Journal of Consumer Research 31(3), 529-539.

URL: https://www.jstor.org/stable/10.1086/425087

Camerer, C. F., Loewenstein, G. and Rabin, M., eds (2003), Advances in Behavioral Economics, Princeton University Press, New York : Princeton, N.J.

Centrica (2018), Centrica Response: Future supply market arrangements - response to call for evidence, Technical report.

URL: https://www.ofgem.gov.uk/publications-and-updates/future-supply-market-arrangements-response-ourcall-evidence

Centrica (n.d.), 'Cornwall Local Energy Market — Centrica plc'.

URL: https://www.centrica.com/innovation/cornwall-local-energy-market

Chambers, C. (2017), The Seven Deadly Sins of Psychology: A Manifesto for Reforming the Culture of Scientific Practice, Princeton University Press.

URL: https://press.princeton.edu/books/hardcover/9780691158907/the-seven-deadly-sins-of-psychology

Chiradeja, P. and Ramakumar, R. (2004), 'An approach to quantify the technical benefits of distributed generation', IEEE Transactions on Energy Conversion 19(4), 764-773.

Chuang, E. and Wykstra, S. (2015), A Guide to Pre-Analysis Plans, Technical report, Innovations for Poverty. URL: https://osf.io/sh4v8/

Citizens Advice (2018), Citizens Advice Response - Future supply market arrangements - response to call for evidence, Technical report.

URL: https://www.ofgem.gov.uk/publications-and-updates/future-supply-market-arrangements-response-ourcall-evidence

Cooper-Martin, E. (1994), 'Measures of cognitive effort', Marketing Letters 5(1), 43-56.

URL: https://doi.org/10.1007/BF00993957

Dinner, I., Johnson, E. J., Goldstein, D. G. and Liu, K. (2011), 'Partitioning default effects: Why people choose not to choose.', Journal of Experimental Psychology: Applied 17(4), 332-341.

URL: http://doi.apa.org/getdoi.cfm?doi=10.1037/a0024354 
DLT (2018), DLT Consulting Response - Future supply market arrangements - response to call for evidence, Technical report.

URL: https://www.ofgem.gov.uk/publications-and-updates/future-supply-market-arrangements-response-ourcall-evidence

Dunn, O. J. (1961), 'Multiple Comparisons Among Means', Journal of the American Statistical Association 56(293), 52-64.

URL: https://www.jstor.org/stable/2282330

Ebeling, F. and Lotz, S. (2015), 'Domestic uptake of green energy promoted by opt-out tariffs', Nature Climate Change 5(9), 868-871.

URL: https://www.nature.com/articles/nclimate2681

EDF (2018), EDF Response - Future supply market arrangements - response to call for evidence, Technical report.

URL: https://www.ofgem.gov.uk/publications-and-updates/future-supply-market-arrangements-response-ourcall-evidence

EDF (n.d.), 'Latest R\&D projects'.

URL: https://www.edfenergy.com/about/research-development/projects

Ek, K. and Söderholm, P. (2008), 'Households' switching behavior between electricity suppliers in Sweden', Utilities Policy 16(4), 254-261.

URL: http://www.sciencedirect.com/science/article/pii/S0957178708000398

ELEXON (2018), ELEXON Response - Future supply market arrangements - response to call for evidence, Technical report.

URL: https://www.ofgem.gov.uk/publications-and-updates/future-supply-market-arrangements-response-ourcall-evidence

Elexon (2019), P379 'Enabling consumers to buy and sell electricity from/to multiple providers through Meter Splitting': Interim Assessment Report, Technical report, London.

URL: https://www.elexon.co.uk/documents/groups/panel/2019-meetings/291-june/291-06-p379-interimassessment-report/

Energy Systems Catapult (2019), Evaluating common themes in Smart Local Energy Systems, Technical report, Energy Systems Catapult, Birmingham.

URL: https://es.catapult.org.uk/news/consumers-welcome-smart-local-energy-systems-in-home-truthssurvey/

E.ON (2018), E.ON Response - Future supply market arrangements - response to call for evidence, Technical report.

URL: https://www.ofgem.gov.uk/publications-and-updates/future-supply-market-arrangements-response-ourcall-evidence

Fell, M. J., Schneiders, A. and Shipworth, D. (2019), 'Consumer Demand for Blockchain-Enabled Peer-to-Peer Electricity Trading in the United Kingdom: An Online Survey Experiment', Energies 12(20), 3913.

URL: https://www.mdpi.com/1996-1073/12/20/3913

Fell, M., Nicolson, M. and Huebner, G. (2017), The Value of Time of Use Tariffs in Great Britain - Citizens Advice, Technical report, Citizens advice.

URL: https://www.citizensadvice.org.uk/about-us/policy/policy-research-topics/energy-policy-research-andconsultation-responses/energy-policy-research/the-value-of-time-of-use-tariffs-in-great-britain/

Fuentes-Bracamontes, R. (2016), 'Is unbundling electricity services the way forward for the power sector?', The Electricity Journal 29(9), 16-20.

URL: http://www.sciencedirect.com/science/article/pii/S1040619016301440

Fuller, M., Kunkel, C., Zimring, M., Hoffman, I., Soroye, K. and Goldman, C. (2010), Driving demand for home energy improvements, Technical report, Environmental Energy Technologies Division Lawrence Berkeley National Laboratory, California.

URL: https://emp.lbl.gov/sites/default/files/report-low-res-bnl-3960e.pdf 
Gächter, S., Johnson, E. and Herrmann, A. (2010), 'Individual-level loss aversion in riskless and risky choices', The University of Nottingham, Centre for Decision Research and Experimental Economics (CeDEx).

Gemserv (2018), Gemserv Response - Future supply market arrangements - response to call for evidence, Technical report.

URL: https://www.ofgem.gov.uk/publications-and-updates/future-supply-market-arrangements-response-ourcall-evidence

Gillingham, K. and Palmer, K. (2014), 'Bridging the Energy Efficiency Gap: Policy Insights from Economic Theory and Empirical Evidence', Review of Environmental Economics and Policy 8(1), 18-38.

URL: https://academic.oup.com/reep/article/8/1/18/1588147

Gui, E. M. and MacGill, I. (2018), 'Typology of future clean energy communities: An exploratory structure, opportunities, and challenges', Energy Research \& Social Science 35, 94-107.

URL: http://www.sciencedirect.com/science/article/pii/S221462961730347X

Hall, S. and Foxon, T. J. (2014), 'Values in the Smart Grid: The co-evolving political economy of smart distribution', Energy Policy 74, 600-609.

URL: http://www.sciencedirect.com/science/article/pii/S0301421514004716

Hall, S. and Roelich, K. (2016), 'Business model innovation in electricity supply markets: The role of complex value in the United Kingdom', Energy Policy 92, 286-298.

Hannon, M. J., Foxon, T. J. and Gale, W. F. (2013), 'The co-evolutionary relationship between Energy Service Companies and the UK energy system: Implications for a low-carbon transition', Energy Policy 61, 10311045.

URL: http://www.sciencedirect.com/science/article/pii/S0301421513004941

Heidig, W., Wentzel, D., Tomczak, T., Wiecek, A. and Faltl, M. (2017), “Supersize me!” The effects of cognitive effort and goal frame on the persuasiveness of upsell offers', Journal of Service Management 28, 00-00.

Huebner, G., Nicolson, M., Fell, M., Shipworth, D., Elam, S., Hanmer, C., Kennard, H. and Johnson, C. (2017), Are we heading towards a replicability crisis in energy efficiency research? A toolkit for improving the quality, transparency and replicability of energy efficiency impact evaluations, in 'Monitoring and Evaluation: Building Confidence and Enhancing Practices'.

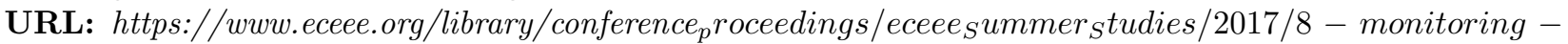
and - evaluation - building - confidence - and - enhancing - practices/are - we - heading - towards $a$ - replicability - crisis - in - energy - efficiency - research - a - toolkit - for - improving - the quality - transparency - and - replicability - of - energy - efficiency - impact - evaluations/

ICoSS (2018), ICoSS Response - Future supply market arrangements - response to call for evidence, Technical report.

URL: https://www.ofgem.gov.uk/publications-and-updates/future-supply-market-arrangements-response-ourcall-evidence

Jachimowicz, J. M., Duncan, S., Weber, E. U. and Johnson, E. J. (2019), 'When and why defaults influence decisions: A meta-analysis of default effects', Behavioural Public Policy pp. 1-28.

URL: https://www.cambridge.org/core/product/identifier/S2398063X1800043X/type/journal rticle

Johnson, D. R. and Creech, J. C. (1983), 'Ordinal Measures in Multiple Indicator Models: A Simulation Study of Categorization Error', American Sociological Review 48(3), 398-407.

URL: https://www.jstor.org/stable/2095231

Johnson, E. J. and Goldstein, D. (2003), 'Do Defaults Save Lives?', Science 302(5649), 1338-1339.

URL: http://science.sciencemag.org/content/302/5649/1338

Juliusson, E. A., Gamble, A. and Gärling, T. (2007), 'Loss aversion and price volatility as determinants of attitude towards and preference for variable price in the Swedish electricity market', Energy Policy 35(11), 59535957.

URL: http://www.sciencedirect.com/science/article/pii/S0301421507002881

Kalkbrenner, B. J. and Roosen, J. (2016), 'Citizens' willingness to participate in local renewable energy projects: The role of community and trust in Germany', Energy Research \& Social Science 13, 60-70.

URL: http://www.sciencedirect.com/science/article/pii/S2214629615300864 
Kalkbrenner, B. J., Yonezawa, K. and Roosen, J. (2017), 'Consumer preferences for electricity tariffs: Does proximity matter?', Energy Policy 107, 413-424.

URL: http://www.sciencedirect.com/science/article/pii/S0301421517302355

Koirala, B. P., Araghi, Y., Kroesen, M., Ghorbani, A., Hakvoort, R. A. and Herder, P. M. (2018), 'Trust, awareness, and independence: Insights from a socio-psychological factor analysis of citizen knowledge and participation in community energy systems', Energy Research \& Social Science 38, 33-40.

URL: http://www.sciencedirect.com/science/article/pii/S2214629618300641

Limejump (2018), Limejump Response - Future supply market arrangements - response to call for evidence, Technical report.

URL: https://www.ofgem.gov.uk/publications-and-updates/future-supply-market-arrangements-response-ourcall-evidence

Littlechild, S. (2005), Smaller Suppliers in the UK Domestic Electricity Market: Experience, Concerns and Policy Recommendations, Technical report, University of Cambridge, Cambridge.

URL: https://www.eprg.group.cam.ac.uk/wp-content/uploads/2014/01/smallersuppliersintheuk.pdf

Lodge, M. and Wegrich, K. (2016), 'The Rationality Paradox of Nudge: Rational Tools of Government in a World of Bounded Rationality', Law \& Policy 38(3), 250-267.

URL: https://onlinelibrary.wiley.com/doi/abs/10.1111/lapo.12056

Mazur, C., Hall, S., Hardy, J. and Workman, M. (2019), 'Technology is not a Barrier: A Survey of Energy System Technologies Required for Innovative Electricity Business Models Driving the Low Carbon Energy Revolution', Energies 12(3), 428.

URL: https://www.mdpi.com/1996-1073/12/3/428

McKenzie, C. R. M., Liersch, M. J. and Finkelstein, S. R. (2006), 'Recommendations implicit in policy defaults', Psychological Science 17(5), 414-420.

Momsen, K. and Stoerk, T. (2014), 'From intention to action: Can nudges help consumers to choose renewable energy?', Energy Policy 74(C), 376-382.

URL: https://ideas.repec.org/a/eee/enepol/v74y2014icp376-382.html

MRA (2018), MRA Response - Future supply market arrangements - response to call for evidence, Technical report.

URL: https://www.ofgem.gov.uk/publications-and-updates/future-supply-market-arrangements-response-ourcall-evidence

Mundaca, L., Busch, H. and Schwer, S. (2018), "Successful' low-carbon energy transitions at the community level? An energy justice perspective', Applied Energy 218, 292-303.

URL: http://www.sciencedirect.com/science/article/pii/S0306261918302848

Nicolson, M., Huebner, G. and Shipworth, D. (2017), 'Are consumers willing to switch to smart time of use electricity tariffs? The importance of loss-aversion and electric vehicle ownership', Energy Research 85 Social Science 23, 82-96.

URL: http://www.sciencedirect.com/science/article/pii/S2214629616302961

Nolan, D. (2017), 'Dermot Nolan's speech to the Energy UK annual conference'.

URL: $\quad$ https://www.ofgem.gov.uk/publications-and-updates/dermot-nolan-s-speech-energy-uk-annualconference

Northern Powergrid (2018), Northern Powergrid Response - Future supply market arrangements - response to call for evidence, Technical report.

URL: https://www.ofgem.gov.uk/publications-and-updates/future-supply-market-arrangements-response-ourcall-evidence

Octopus Energy (2018), Octopus Energy Response - Future supply market arrangements - response to call for evidence, Technical report.

URL: https://www.ofgem.gov.uk/publications-and-updates/future-supply-market-arrangements-response-ourcall-evidence 
Ofgem (2011), What can behavioural economics say about GB energy consumers?, Technical report, Office for Gas and Electricity Markets, London.

URL: https://www.ofgem.gov.uk/ofgem-publications/39711/behaviouraleconomicsgbenergy.pdf

Ofgem (2017a), Local energy in a transforming energy system, Technical report, Office for Gas and Electricity Markets, London.

URL: $\quad$ https://www.ofgem.gov.uk/publications-and-updates/ofgem-future-insights-series-local-energytransforming-energy-system

Ofgem (2017b), State of the energy market 2017, Technical report, Office for Gas and Electricity Markets, London.

URL: https://www.ofgem.gov.uk/publications-and-updates/state-energy-market-2017

Ofgem (2018a), Future supply market arrangements - response to our call for evidence, Technical report, Office for Gas and Electricity Markets, London.

URL: https://www.ofgem.gov.uk/publications-and-updates/future-supply-market-arrangements-response-ourcall-evidence

Ofgem (2018b), State of the energy market 2018, Technical report, Office for Gas and Electricity Markets, London.

URL: https://www.ofgem.gov.uk/publications-and-updates/state-energy-market-2018

Ofgem (2019), 'Electricity supply market shares by company: Domestic (GB)'.

URL: https://www.ofgem.gov.uk/data-portal/electricity-supply-market-shares-company-domestic-gb

ONS (2018), Internet access - households and individuals, Great Britain - Office for National Statistics, Technical report, Office for National Statistics, London.

URL: https://www.ons.gov.uk/peoplepopulationandcommunity/householdcharacteristics/homeinternetandsocialmediausag

ONS (2019), Population estimates - 2018, Technical report, Office for National Statistics, London.

URL: https://www.ons.gov.uk/peoplepopulationandcommunity/populationandmigration/populationestimates

Pichert, D. and Katsikopoulos, K. V. (2008), 'Green defaults: Information presentation and pro-environmental behaviour', Journal of Environmental Psychology 28(1), 63-73.

Rau, H. A. (2014), 'The disposition effect and loss aversion: Do gender differences matter?', Economics Letters 123(1), 33-36.

URL: http://www.sciencedirect.com/science/article/pii/S0165176514000287

Richter, M. (2012), 'Utilities' business models for renewable energy: A review', Renewable and Sustainable Energy Reviews 16.

Rogers, J. C., Simmons, E. A., Convery, I. and Weatherall, A. (2008), 'Public perceptions of opportunities for community-based renewable energy projects', Energy Policy 36(11), 4217-4226.

URL: http://www.sciencedirect.com/science/article/pii/S0301421508003662

Rosenow, J. and Porter, F. (2015), A Comparative Review of Housing Energy Efficiency Interventions, Technical report, ClimateXChange.

URL: https://www.climatexchange.org.uk/media/1403/final eport $_{2} 61015 . p d f$

Sagebiel, J., Müller, J. R. and Rommel, J. (2014), 'Are consumers willing to pay more for electricity from cooperatives? Results from an online Choice Experiment in Germany', Energy Research Er Social Science 2, 90-101.

URL: http://www.sciencedirect.com/science/article/pii/S221462961400036X

Samuelson, W. and Zeckhauser, R. (1988), 'Status quo bias in decision making', Journal of Risk and Uncertainty 1(1), 7-59.

URL: https://doi.org/10.1007/BF00055564

Schmid, B., Meister, T., Klagge, B. and Seidl, I. (2019), 'Energy Cooperatives and Municipalities in Local Energy Governance Arrangements in Switzerland and Germany', The Journal of Environment Es Development 29(1), 123-146.

URL: https://doi.org/10.117r/1070496519886013 
Simon, H. A. (1997), Administrative Behavior, 4th Edition: A Study of Decision-Making Processes in Administrative Organisations, 4rev ed edition edn, Free Press, New York.

Smartest Energy (2018), Smartest Energy Response - Future supply market arrangements - response to call for evidence, Technical report.

URL: https://www.ofgem.gov.uk/publications-and-updates/future-supply-market-arrangements-response-ourcall-evidence

Spence, J. (2018), Enabling customers to buy power from multiple providers, Technical report, Elexon.

URL: https://www.elexon.co.uk/about/innovation-developments-industry/enabling-customers-buy-powermultiple-providers /

Sustainability First (2018), Sustainability First Response - Future supply market arrangements - response to call for evidence, Technical report.

URL: https://www.ofgem.gov.uk/publications-and-updates/future-supply-market-arrangements-response-ourcall-evidence

Thaler, R. H. and Sunstein, C. R. (2008), Nudge: Improving Decisions About Health, Wealth and Happiness, Penguin, London.

Tversky, A. and Kahneman, D. (1974), 'Judgment under Uncertainty: Heuristics and Biases', Science 185(4157), 1124-1131.

URL: https://science.sciencemag.org/content/185/4157/1124

Tversky, A. and Kahneman, D. (1991), 'Loss Aversion in Riskless Choice: A Reference-Dependent Model', The Quarterly Journal of Economics 106(4), 1039-1061.

URL: https://www.jstor.org/stable/2937956

van der Schoor, T. and Scholtens, B. (2015), 'Power to the people: Local community initiatives and the transition to sustainable energy', Renewable and Sustainable Energy Reviews 43, 666-675.

URL: http://www.sciencedirect.com/science/article/pii/S1364032114009149

Vetter, M. and Kutzner, F. (2016), 'Nudge me if you can - how defaults and attitude strength interact to change behavior', Comprehensive Results in Social Psychology 1(1-3), 8-34.

URL: https://doi.org/10.1080/23743603.2016.1139390

Walker, G., Devine-Wright, P., Hunter, S., High, H. and Evans, B. (2010), 'Trust and community: Exploring the meanings, contexts and dynamics of community renewable energy', Energy Policy 38(6), 2655-2663.

URL: http://www.sciencedirect.com/science/article/pii/S0301421509003541

Walker, G. and Simcock, N. (2012), Community Energy Systems, in 'International Encyclopedia of Housing and Home', Elsevier Science, pp. 194-198.

Walsh, G., Groth, M. and Wiedmann, K.-P. (2005), 'An Examination of Consumers' Motives to Switch Energy Suppliers', Journal of Marketing Management 21(3-4), 421-440.

URL: https://doi.org/10.1362/0267257053779091

Wegner, M.-S., Hall, S., Hardy, J. and Workman, M. (2017), 'Valuing energy futures; a comparative analysis of value pools across UK energy system scenarios', Applied Energy 206, 815-828.

URL: http://www.sciencedirect.com/science/article/pii/S0306261917312333

Wiersma, B. and Devine-Wright, P. (2014), 'Decentralising energy: Comparing the drivers and influencers of projects led by public, private, community and third sector actors', Contemporary Social Science 9(4), 456470.

URL: https://doi.org/10.1080/21582041.2014.981757

Willis, G. B. (2005), Cognitive Interviewing: A Tool for Improving Questionnaire Design / Gordon B. Willis., Sage Publications, SAGE, Thousand Oaks, Calif. ; London, Thousand Oaks ; London.

URL: http://methods.sagepub.com/book/cognitive-interviewing

Wilson, C. and Dowlatabadi, H. (2007), 'Models of Decision Making and Residential Energy Use', Annual Review of Environment and Resources 32(1), 169-203.

URL: https://doi.org/10.1146/annurev.energy.32.053006.141137 
Wright, K. B. (2005), 'Researching Internet-Based Populations: Advantages and Disadvantages of Online Survey Research, Online Questionnaire Authoring Software Packages, and Web Survey Services', Journal of Computer-Mediated Communication 10(3).

URL: https://academic.oup.com/jcmc/article/10/3/JCMC1034/4614509

Zhang, C., Wu, J., Long, C. and Cheng, M. (2017), 'Review of Existing Peer-to-Peer Energy Trading Projects', Energy Procedia 105, 2563-2568.

URL: http://www.sciencedirect.com/science/article/pii/S1876610217308007 


\section{Appendix A}

\section{Treatments}

Figure 8: Treatments for default mechanisms experiment (experiment one), single supplier default group (top) and multiple supplier default group (bottom)
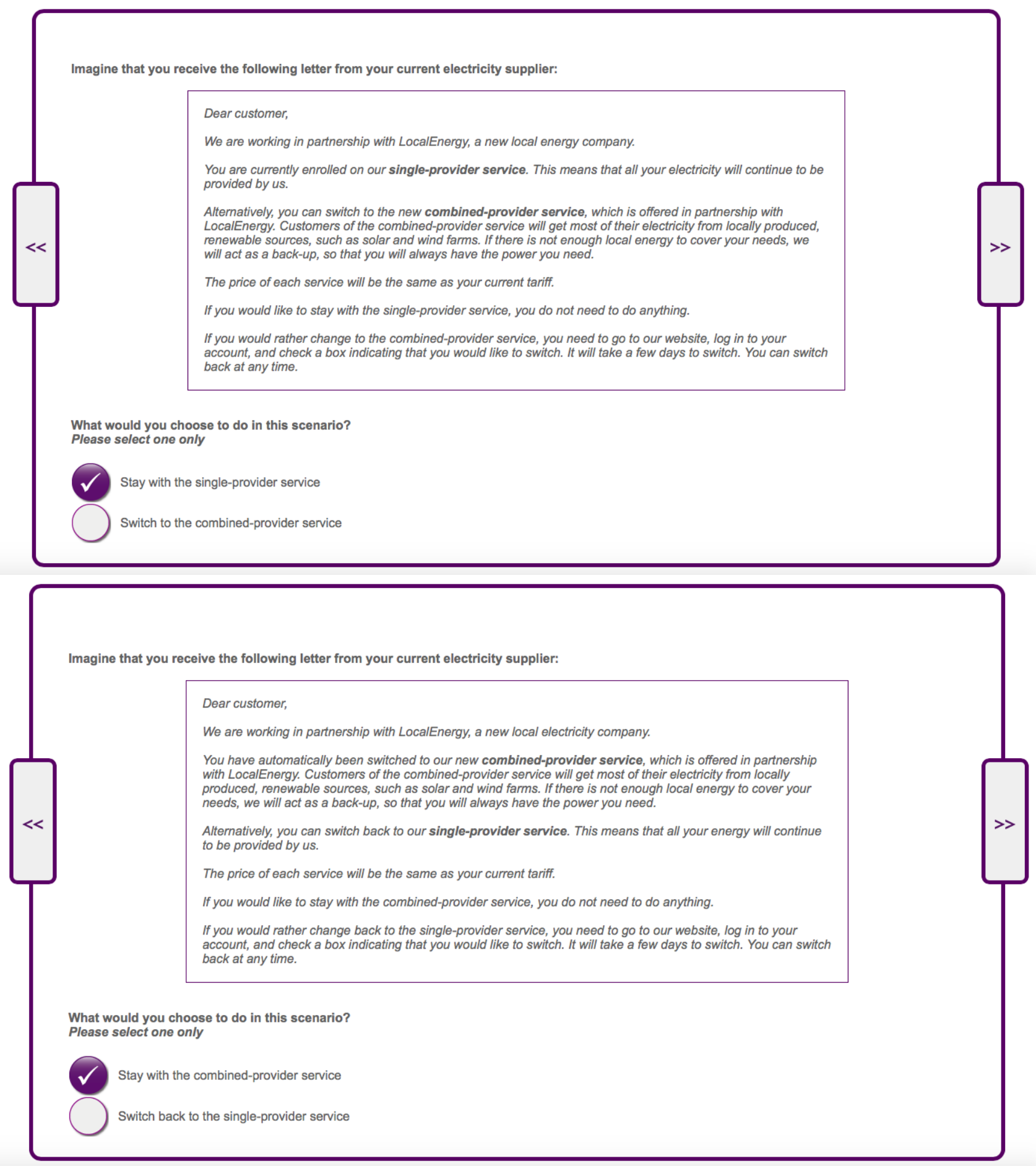
Figure 9: Treatments for default mechanisms experiment (experiment one), active choice group (order randomised)

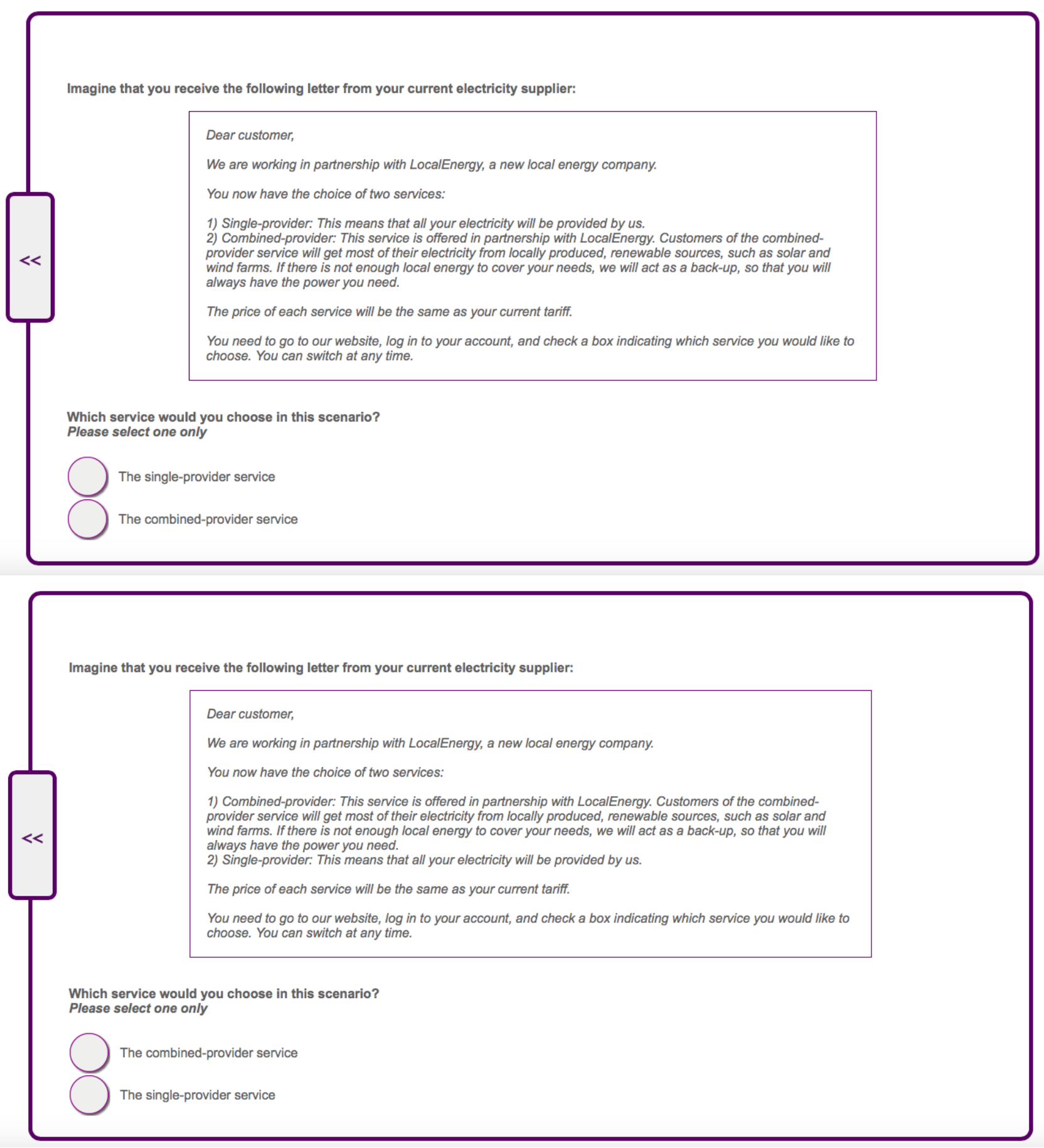


Figure 10: Treatments for consumer preferences experiment (experiment two), single supplier condition (top), multiple supplier condition (bottom)

\section{PopulusLive}

Imagine that you receive the following letter from a new local energy supplier that has recently set up in your area:

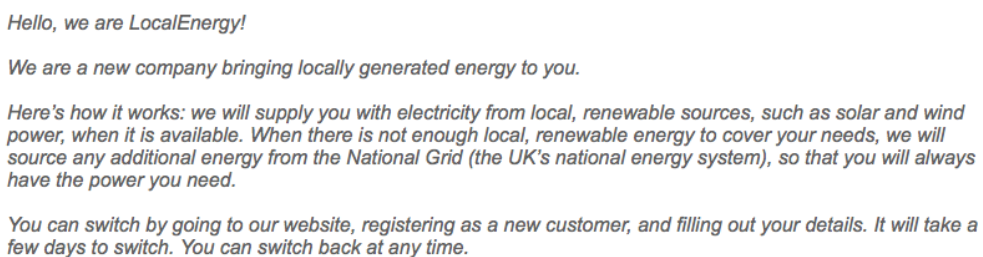

You can switch by going to our website, registering as a new customer, and filling out your details. It will take a few days to switch. You can switch back at any time.

LocalEnergy's tariff costs the same as your current tariff.

What would you do in this scenario?

Please select one only

Stay with my current supplier

Switch to LocalEnergy

PopulusLive

Imagine that you receive the following letter from a new local energy supplier that has recently set up in your area:

Hello, we are LocalEnergy!

We are a new company working in partnership with existing energy suppliers to bring locally generated energy to you.

Here's how it works: if you add us on to your existing tariff, we will supply you with electricity from local, renewable sources, such as solar and wind power, when it is available. When there is not enough local,

renewable energy to cover your needs, your existing supplier will act as a back-up, so that you will always have

the power you need.

You can add our services on to your existing tariff by going to your current supplier's website, logging in to your account, and registering your interest. It could take a few days to add this service on. You can switch back at any time.

This combined-provider service costs the same as your current tariff.

What would you do in this scenario?

Please select one only

Stay with my current tariff

Add LocalEnergy's services to my current tariff 


\section{Appendix B}

7.1. Measures of cognitive biases

Figure 11: Cognitive effort measure

PopulusLive

$16 \%$

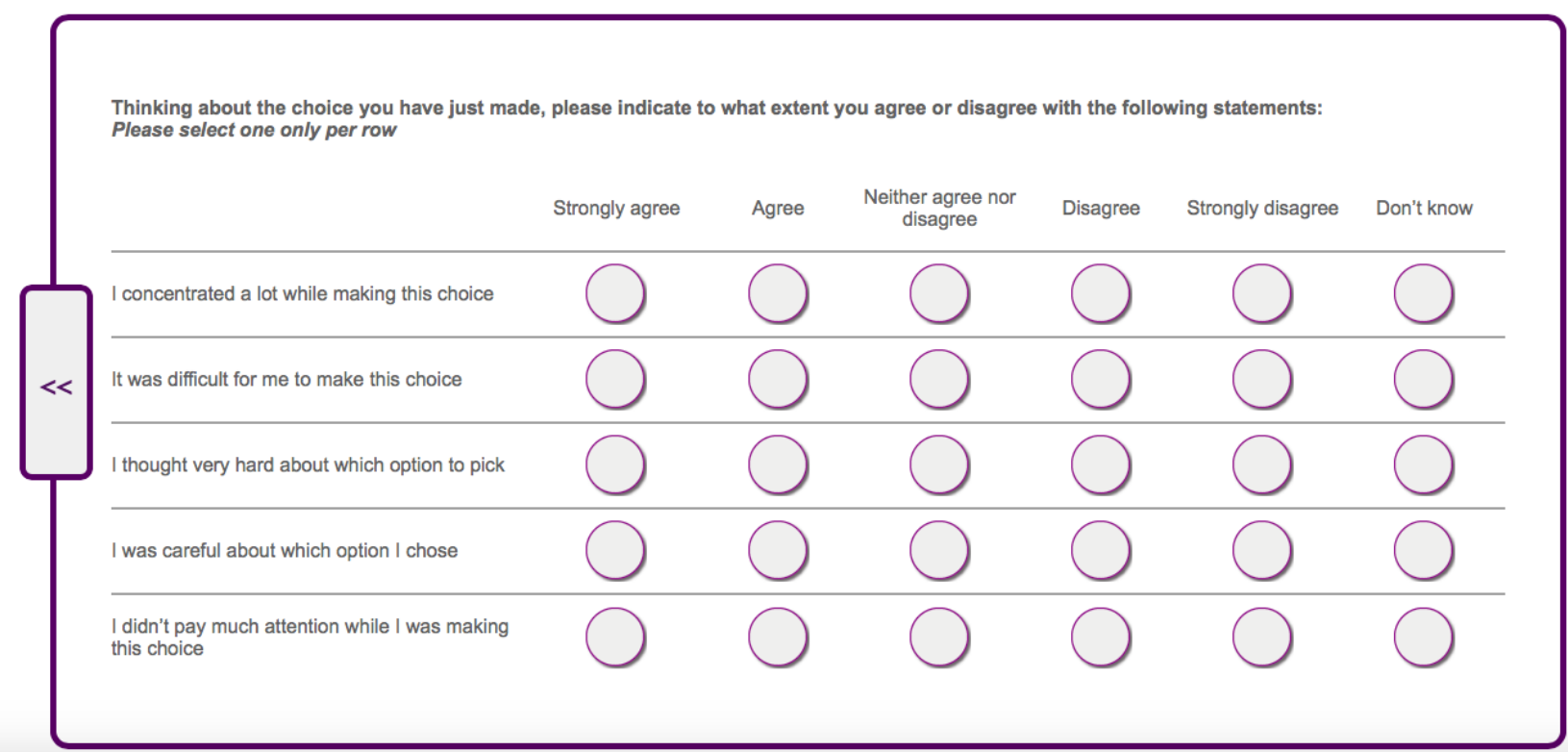

PopulusLive

Figure 12: Implied endorsement measure (highlighted) with buffer questions

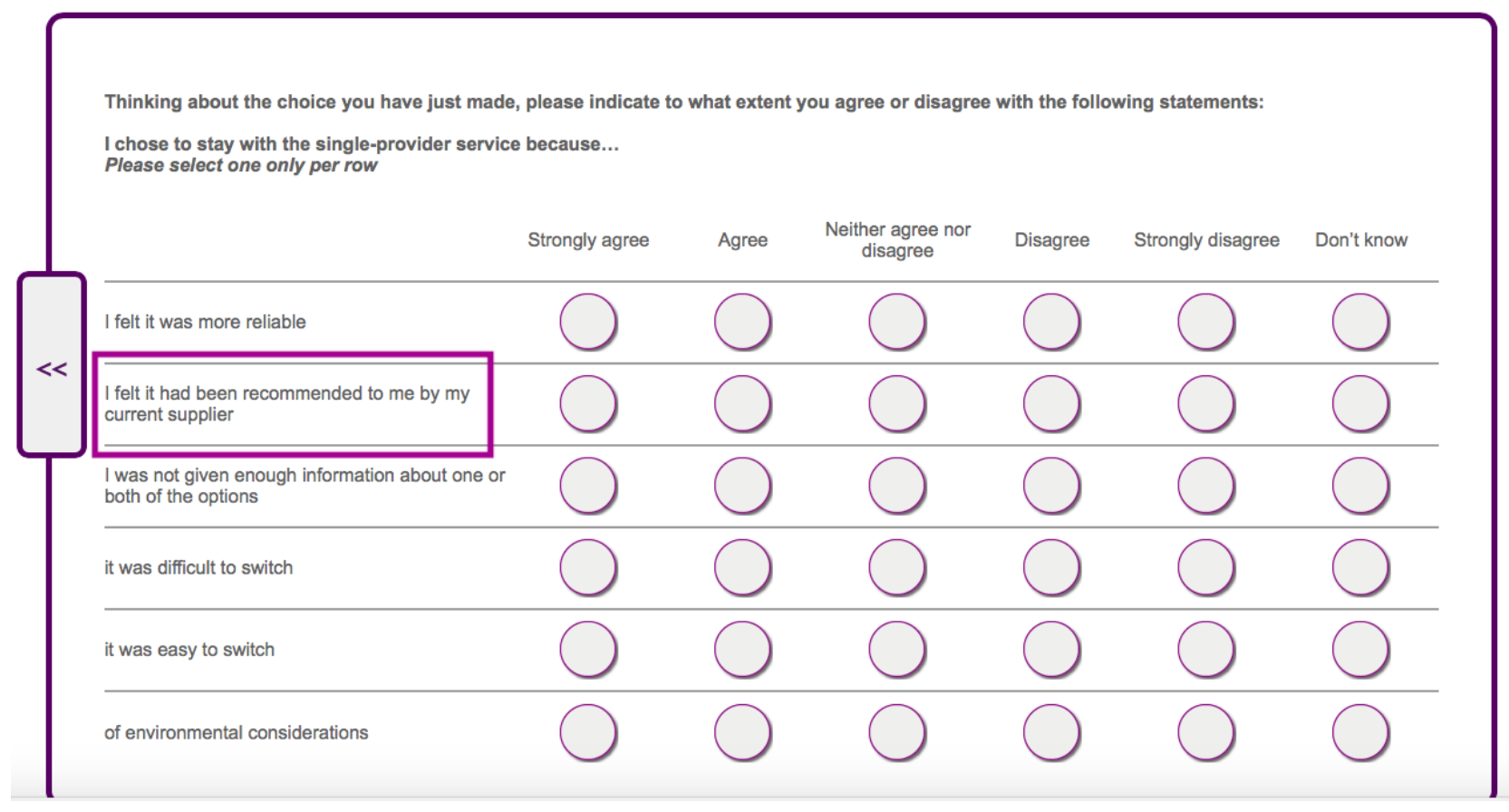


Figure 13: Loss-aversion measure

Please imagine that you are offered the opportunity to take a series of coin flipping 'heads or tails' gambles and then tell us whether you would take the gamble in each case.

- if you take the gamble, then you could hypothetically win or lose money

- if you don't take the gamble, then you can't win or lose anything

Please remember that there are no right or wrong answers for these questions - it is just about your preferences. Please select one only per row

If the coin turns up heads then you lose £2; if the coin turns up tails then you win £6

If the coin turns up heads then you lose $£ 3$; if the coin turns up tails then you win £6

If the coin turns up heads then you lose $£ 4$; if the coin turns up tails then you win £6

If the coin turns up heads then you lose $£ 5$; if the coin turns up tails then you win £6

If the coin turns up heads then you lose $£ 6$; if the coin turns up tails then you win $£ 6$

If the coin turns up heads then you lose $£ 7$; if the coin turns up tails then you win $£ 6$ 
Appendix C

7.2. Full models 
Table 4: Full odds ratios - experiment 1 (default mechanisms)

\begin{tabular}{|c|c|c|c|}
\hline & Model 1 & Model 2 & Model 3 \\
\hline \multirow[t]{2}{*}{ Single supplier group } & 7.795 & 8.273 & 4.007 \\
\hline & $(5.57-11.038)$ & $(5.789-11.983)$ & $(0.325-54.205)$ \\
\hline \multirow[t]{2}{*}{ Cognitive effort } & 1.243 & 1.318 & 1.760 \\
\hline & $(0.981-1.581)$ & $(1.018-1.714)$ & $(1.158-2.748)$ \\
\hline \multirow[t]{2}{*}{ Implied endorsement } & 0.912 & 0.947 & 0.496 \\
\hline & $(0.768-1.082)$ & $(0.788-1.138)$ & $(0.358-0.680)$ \\
\hline \multirow[t]{2}{*}{ Loss-aversion } & 1.038 & 1.042 & 1.308 \\
\hline & $(0.910-1.185)$ & $(0.900-1.209)$ & $(1.009-1.730)$ \\
\hline \multirow[t]{2}{*}{ Single supplier group:cognitive effort } & & & 0.654 \\
\hline & & & $(0.376-1.118)$ \\
\hline \multirow[t]{2}{*}{ Single supplier group: implied endorsement } & & & 2.700 \\
\hline & & & $(1.833-4.020)$ \\
\hline \multirow[t]{2}{*}{ Single supplier group: loss-aversion } & & & 0.719 \\
\hline & & & $(0.518-0.982)$ \\
\hline \multirow[t]{2}{*}{ Male } & & 1.009 & 1.039 \\
\hline & & $(0.706-1.442)$ & $(0.721-1.498)$ \\
\hline \multirow[t]{2}{*}{ Age } & & 0.961 & 0.956 \\
\hline & & $(0.851-1.085)$ & $(0.843-1.085)$ \\
\hline \multirow[t]{2}{*}{ Education: secondary school } & & 1.259 & 1.517 \\
\hline & & $(0.448-3.824)$ & $(0.518-4.782)$ \\
\hline \multirow[t]{2}{*}{ Education: degree or higher } & & 1.135 & 1.313 \\
\hline & & $(0.402-3.459)$ & $(0.447-4.147)$ \\
\hline \multirow[t]{2}{*}{ Private renter } & & 0.774 & 0.737 \\
\hline & & $(0.463-1.281)$ & $(0.434-1.243)$ \\
\hline \multirow[t]{2}{*}{ Social renter } & & 0.872 & 0.878 \\
\hline & & $(0.542-1.397)$ & $(0.539-1.425)$ \\
\hline \multirow[t]{2}{*}{ Rent free } & & 0.949 & 0.844 \\
\hline & & $(0.299-2.845)$ & $(0.269-2.510)$ \\
\hline \multirow[t]{2}{*}{ Moved house within last 12 months } & & 1.743 & 1.878 \\
\hline & & $(0.862-3.495)$ & $(0.894-3.946)$ \\
\hline \multirow[t]{2}{*}{ Satisfaction with energy supplier } & & 1.057 & 1.112 \\
\hline & & $(0.892-1.254)$ & $(0.935-1.325)$ \\
\hline \multirow[t]{2}{*}{ Don't know if switched tariff/supplier } & & 1.558 & 1.702 \\
\hline & & $(0.907-2.676)$ & $(0.974-2.981)$ \\
\hline \multirow[t]{2}{*}{ Switched tariff/supplier more than 12 months ago } & & 1.364 & 1.389 \\
\hline & & $(0.917-2.033)$ & $(0.925-2.090)$ \\
\hline \multirow[t]{2}{*}{ Switched tariff/supplier within last 12 months } & & 1.038 & 1.045 \\
\hline & & $(0.435-2.39)$ & $(0.433-2.458)$ \\
\hline \multirow[t]{2}{*}{ Switched tariff/supplier within last 3 months } & & 0.211 & 0.110 \\
\hline & & $(0.010-1.750)$ & $(0.005-1.013)$ \\
\hline \multirow[t]{2}{*}{ Income $£ 21,001-£ 41,000$} & & 1.110 & 1.127 \\
\hline & & $(0.753-1.635)$ & $(0.757-1.679)$ \\
\hline \multirow[t]{2}{*}{ Income $£ 41,000+$} & & 0.654 & 0.668 \\
\hline & & $(0.359-1.177)$ & $(0.363-1.215)$ \\
\hline
\end{tabular}


Table 5: Logistic regression coefficients and p values - experiment 1 (default mechanisms)

\begin{tabular}{|c|c|c|c|}
\hline & \multicolumn{3}{|c|}{ Dependent variable: } \\
\hline & \multicolumn{3}{|c|}{ Switching away from default } \\
\hline & $(1)$ & $(2)$ & $(3)$ \\
\hline Single supplier group & $\begin{array}{c}2.054^{* * *} \\
\mathrm{p}=0.000\end{array}$ & $\begin{array}{c}2.113^{* * *} \\
\mathrm{p}=0.000\end{array}$ & $\begin{aligned} & 1.388 \\
\mathrm{p}= & 0.287\end{aligned}$ \\
\hline Cognitive effort & $\begin{array}{c}0.218^{*} \\
\mathrm{p}=0.074\end{array}$ & $\begin{array}{c}0.276^{* *} \\
\mathrm{p}=0.038\end{array}$ & $\begin{array}{c}0.565^{* *} \\
\mathrm{p}=0.011\end{array}$ \\
\hline Implied endorsement & $\begin{array}{c}-0.092 \\
\mathrm{p}=0.290\end{array}$ & $\begin{array}{c}-0.055 \\
\mathrm{p}=0.562\end{array}$ & $\begin{array}{c}-0.700^{* * *} \\
\mathrm{p}=0.00002\end{array}$ \\
\hline Loss-aversion & $\begin{array}{c}0.038 \\
\mathrm{p}=0.577\end{array}$ & $\begin{array}{c}0.041 \\
\mathrm{p}=0.582\end{array}$ & $\begin{array}{c}0.268^{* *} \\
\mathrm{p}=0.050\end{array}$ \\
\hline Single supplier group:cognitive effort & & & $\begin{array}{c}-0.425 \\
\mathrm{p}=0.126\end{array}$ \\
\hline Single supplier group: implied endorsement & & & $\begin{array}{c}0.993^{* * *} \\
\mathrm{p}=0.00000\end{array}$ \\
\hline Single supplier group: loss-aversion & & & $\begin{array}{c}-0.330^{* *} \\
\mathrm{p}=0.043\end{array}$ \\
\hline Male & & $\begin{array}{c}0.009 \\
\mathrm{p}=0.960\end{array}$ & $\begin{array}{c}0.038 \\
\mathrm{p}=0.838\end{array}$ \\
\hline Age & & $\begin{array}{c}-0.040 \\
\mathrm{p}=0.523\end{array}$ & $\begin{array}{c}-0.045 \\
\mathrm{p}=0.487\end{array}$ \\
\hline Education: secondary school & & $\begin{array}{c}0.230 \\
\mathrm{p}=0.672\end{array}$ & $\begin{array}{c}0.417 \\
\mathrm{p}=0.459\end{array}$ \\
\hline Education: degree or higher & & $\begin{array}{c}0.127 \\
\mathrm{p}=0.816\end{array}$ & $\begin{array}{c}0.273 \\
\mathrm{p}=0.629\end{array}$ \\
\hline Private renter & & $\begin{array}{c}-0.256 \\
\mathrm{p}=0.323\end{array}$ & $\begin{array}{c}-0.305 \\
\mathrm{p}=0.256\end{array}$ \\
\hline Rent free & & $\begin{array}{c}-0.053 \\
\mathrm{p}=0.927\end{array}$ & $\begin{array}{c}-0.170 \\
\mathrm{p}=0.763\end{array}$ \\
\hline Social renter & & $\begin{array}{c}-0.137 \\
\mathrm{p}=0.571\end{array}$ & $\begin{array}{c}-0.130 \\
\mathrm{p}=0.600\end{array}$ \\
\hline Moved house within last 12 months & & $\begin{array}{c}0.556 \\
\mathrm{p}=0.119\end{array}$ & $\begin{array}{c}0.630^{*} \\
\mathrm{p}=0.095\end{array}$ \\
\hline Satisfaction with energy supplier & & $\begin{array}{c}0.055 \\
\mathrm{p}=0.524\end{array}$ & $\begin{array}{c}0.106 \\
\mathrm{p}=0.231\end{array}$ \\
\hline Don't know if switched tariff/supplier & & $\begin{array}{c}0.443 \\
\mathrm{p}=0.108\end{array}$ & $\begin{array}{c}0.532^{*} \\
\mathrm{p}=0.062\end{array}$ \\
\hline Switched tariff/supplier more than 12 months ago & & $\begin{array}{c}0.311 \\
\mathrm{p}=0.126\end{array}$ & $\begin{array}{c}0.328 \\
\mathrm{p}=0.114\end{array}$ \\
\hline Switched tariff/supplier within last 12 months & & $\begin{array}{c}0.037 \\
\mathrm{p}=0.932\end{array}$ & $\begin{array}{c}0.044 \\
\mathrm{p}=0.922\end{array}$ \\
\hline Switched tariff/supplier within last 3 months & & $\begin{array}{c}-1.555 \\
\mathrm{p}=0.202\end{array}$ & $\begin{array}{c}-2.206^{*} \\
\mathrm{p}=0.082\end{array}$ \\
\hline Income: $£ 21,001-£ 41,000$ & & $\begin{array}{c}0.104 \\
\mathrm{p}=0.599\end{array}$ & $\begin{array}{c}0.120 \\
\mathrm{p}=0.556\end{array}$ \\
\hline Income: $£ 41,001+$ & & $\begin{array}{c}-0.424 \\
\mathrm{p}=0.161\end{array}$ & $\begin{array}{c}-0.404 \\
\mathrm{p}=0.190\end{array}$ \\
\hline Observations & 776 & 714 & 714 \\
\hline Log Likelihood & -426.388 & -385.028 & -368.747 \\
\hline Akaike Inf. Crit. & 862.776 & 810.055 & 783.493 \\
\hline
\end{tabular}


Table 6: Full odds ratios: Experiment 2 (consumer preferences)

\begin{tabular}{|c|c|c|}
\hline & Model 1 & Model 2 \\
\hline Multiple supplier condition & $\begin{array}{c}1.567 \\
(1.135-2.167)\end{array}$ & $\begin{array}{c}1.258 \\
(0.582-2.726)\end{array}$ \\
\hline loss-aversion & $\begin{array}{c}0.970 \\
(0.849-1.109)\end{array}$ & $\begin{array}{c}0.933 \\
(0.778-1.119)\end{array}$ \\
\hline Multiple supplier condition: loss-aversion & & $\begin{array}{c}1.085 \\
(0.837-1.406)\end{array}$ \\
\hline Cognitive effort & $\begin{array}{c}1.107 \\
(0.856-1.435)\end{array}$ & $\begin{array}{c}1.108 \\
(0.857-1.436)\end{array}$ \\
\hline Male & $\begin{array}{c}0.868 \\
(0.624-1.206)\end{array}$ & $\begin{array}{c}0.865 \\
(0.622-1.202)\end{array}$ \\
\hline Age & $\begin{array}{c}0.974 \\
(0.866-1.095)\end{array}$ & $\begin{array}{c}0.973 \\
(0.866-1.094)\end{array}$ \\
\hline Education: secondary school & $\begin{array}{c}0.613 \\
(0.245-1.551)\end{array}$ & $\begin{array}{c}0.612 \\
(0.244-1.547)\end{array}$ \\
\hline Education: degree or higher & $\begin{array}{c}0.907 \\
(0.359-2.306)\end{array}$ & $\begin{array}{c}0.901 \\
(0.357-2.291)\end{array}$ \\
\hline Private renter & $\begin{array}{c}1.864 \\
(1.173-2.976)\end{array}$ & $\begin{array}{c}1.877 \\
(1.180-3.000)\end{array}$ \\
\hline Social renter & $\begin{array}{c}0.937 \\
(0.589-1.478)\end{array}$ & $\begin{array}{c}0.937 \\
(0.589-1.478)\end{array}$ \\
\hline Rent free & $\begin{array}{c}2.293 \\
(0.718-8.015)\end{array}$ & $\begin{array}{c}2.313 \\
(0.724-8.092)\end{array}$ \\
\hline Moved house within last 12 months & $\begin{array}{c}0.929 \\
(0.506-1.689)\end{array}$ & $\begin{array}{c}0.926 \\
(0.505-1.684)\end{array}$ \\
\hline Satisfaction with energy supplier & $\begin{array}{c}0.858 \\
(0.734-1.002)\end{array}$ & $\begin{array}{c}0.859 \\
(0.735-1.002)\end{array}$ \\
\hline Don't know if switched tariff/supplier & $\begin{array}{c}1.147 \\
(0.676-1.936)\end{array}$ & $\begin{array}{c}1.136 \\
(0.669-1.920)\end{array}$ \\
\hline Switched tariff/supplier more than 12 months ago & $\begin{array}{c}1.362 \\
(0.949-1.958)\end{array}$ & $\begin{array}{c}1.349 \\
(0.939-1.943)\end{array}$ \\
\hline Switched tariff/supplier within last 12 months & $\begin{array}{c}1.278 \\
(0.550-2.902)\end{array}$ & $\begin{array}{c}1.288 \\
(0.555-2.922)\end{array}$ \\
\hline Switched tariff/supplier within last 3 months & $\begin{array}{c}0.153 \\
(0.008-0.827)\end{array}$ & $\begin{array}{c}0.151 \\
(0.008-0.817)\end{array}$ \\
\hline Income $£ 21,001-£ 41,000$ & $\begin{array}{c}1.084 \\
(0.764-1.539)\end{array}$ & $\begin{array}{c}1.075 \\
(0.757-1.527)\end{array}$ \\
\hline Income $£ 41,000+$ & $\begin{array}{c}1.437 \\
(0.807-2.564)\end{array}$ & $\begin{array}{c}1.458 \\
(0.817-2.608)\end{array}$ \\
\hline
\end{tabular}


Table 7: Logistic regression coefficients and p values - experiment 2 (consumer preferences)

\begin{tabular}{|c|c|c|}
\hline & \multicolumn{2}{|c|}{ Dependent variable: } \\
\hline & \multicolumn{2}{|c|}{ Switching to/adding Local energy supplie } \\
\hline & (1) & $(2)$ \\
\hline Combined supplier group & $\begin{array}{c}0.449^{* * *} \\
\mathrm{p}=0.007\end{array}$ & $\begin{array}{c}0.229 \\
\mathrm{p}=0.560\end{array}$ \\
\hline \multirow[t]{2}{*}{ Loss-aversion } & -0.031 & -0.069 \\
\hline & $\mathrm{p}=0.654$ & $\mathrm{p}=0.456$ \\
\hline Combined supplier group: loss-aversion & & $\begin{array}{c}0.081 \\
\mathrm{p}=0.539\end{array}$ \\
\hline \multirow[t]{2}{*}{$\overline{\text { Cognitive effort }}$} & 0.102 & 0.103 \\
\hline & $\mathrm{p}=0.441$ & $\mathrm{p}=0.436$ \\
\hline \multirow[t]{2}{*}{ Male } & -0.142 & -0.145 \\
\hline & $\mathrm{p}=0.399$ & $\mathrm{p}=0.390$ \\
\hline \multirow[t]{2}{*}{ Age } & -0.027 & -0.027 \\
\hline & $\mathrm{p}=0.654$ & $\mathrm{p}=0.648$ \\
\hline \multirow[t]{2}{*}{ Secondary school education } & -0.489 & -0.492 \\
\hline & $\mathrm{p}=0.295$ & $\mathrm{p}=0.292$ \\
\hline \multirow[t]{2}{*}{ Education: degree or higher } & -0.098 & -0.105 \\
\hline & $\mathrm{p}=0.836$ & $\mathrm{p}=0.824$ \\
\hline \multirow[t]{2}{*}{ Private rent } & $0.622^{* * *}$ & $0.629^{* * *}$ \\
\hline & $\mathrm{p}=0.009$ & $\mathrm{p}=0.009$ \\
\hline \multirow[t]{2}{*}{ Rent free } & 0.830 & 0.839 \\
\hline & $\mathrm{p}=0.169$ & $\mathrm{p}=0.164$ \\
\hline \multirow[t]{2}{*}{ Social rent } & -0.065 & -0.065 \\
\hline & $\mathrm{p}=0.782$ & $\mathrm{p}=0.781$ \\
\hline \multirow[t]{2}{*}{ Moved house within 12 months } & -0.074 & -0.077 \\
\hline & $\mathrm{p}=0.810$ & $\mathrm{p}=0.802$ \\
\hline \multirow[t]{2}{*}{ Satisfaction with energy supplier } & $-0.153^{*}$ & $-0.153^{*}$ \\
\hline & $\mathrm{p}=0.053$ & $\mathrm{p}=0.054$ \\
\hline \multirow[t]{2}{*}{ Don't know when switched tariff/supplier } & 0.137 & 0.128 \\
\hline & $\mathrm{p}=0.610$ & $\mathrm{p}=0.634$ \\
\hline \multirow[t]{2}{*}{ Switched tariff/supplier more than 12 months ago } & $0.309^{*}$ & 0.300 \\
\hline & $\mathrm{p}=0.095$ & $\mathrm{p}=0.106$ \\
\hline \multirow[t]{2}{*}{ Switched tariff/supplier within 12 months } & 0.245 & 0.253 \\
\hline & $\mathrm{p}=0.560$ & $\mathrm{p}=0.548$ \\
\hline \multirow[t]{2}{*}{ Switched tariff/supplier within 3 months } & $-1.877^{*}$ & $-1.889^{*}$ \\
\hline & $\mathrm{p}=0.077$ & $\mathrm{p}=0.076$ \\
\hline \multirow[t]{2}{*}{ Income: $£ 21,001-£ 41,000$} & 0.081 & 0.072 \\
\hline & $\mathrm{p}=0.651$ & $\mathrm{p}=0.687$ \\
\hline \multirow[t]{2}{*}{ Income: $£ 41,001+$} & 0.363 & 0.377 \\
\hline & $\mathrm{p}=0.219$ & $\mathrm{p}=0.202$ \\
\hline Observations & 664 & 664 \\
\hline Log Likelihood & -429.538 & -429.348 \\
\hline Akaike Inf. Crit. & 897.075 & 898.697 \\
\hline
\end{tabular}




\section{Appendix D}

\subsection{Robustness tests}

Please note, coefficients are presented in odds ratios in the main text and logistic regression coefficients in Appendix D. For odds ratios for all robustness tests, please see replication code available at https://github.com/Watson310N/Multiple-suppliers-paper-materials.

\subsubsection{Model specification - OLS regression models and regional fixed effects}

Table 8: OLS Regression Models and regional fixed effects - experiment 1 (default mechanisms)

\begin{tabular}{|c|c|c|c|c|c|}
\hline & \multicolumn{5}{|c|}{ Dependent variable: } \\
\hline & \multicolumn{5}{|c|}{ Switching away from default } \\
\hline & \multicolumn{3}{|c|}{ OLS regression models } & \multicolumn{2}{|c|}{ Logistic regression models with regional fixed effects } \\
\hline & (1) & $(2)$ & (3) & (4) & $(5)$ \\
\hline Single supplier group & $\begin{array}{c}0.433^{* * *} \\
\mathrm{p}=0.000\end{array}$ & $\begin{array}{c}0.438^{* * *} \\
\mathrm{p}=0.000\end{array}$ & $\begin{array}{c}0.142 \\
\mathrm{p}=0.510\end{array}$ & $\begin{array}{c}2.175^{* * *} \\
\mathrm{p}=0.000\end{array}$ & $\begin{array}{c}1.539 \\
\mathrm{p}=0.247\end{array}$ \\
\hline Cognitive effort & $\begin{array}{c}0.039^{*} \\
\mathrm{p}=0.077\end{array}$ & $\begin{array}{c}0.047^{* *} \\
\mathrm{p}=0.046\end{array}$ & $\begin{array}{c}0.066^{* *} \\
\mathrm{p}=0.029\end{array}$ & $\begin{array}{c}0.276^{* *} \\
\mathrm{p}=0.042\end{array}$ & $\begin{array}{c}0.584^{* * *} \\
\mathrm{p}=0.010\end{array}$ \\
\hline Implied endorsement & $\begin{array}{c}-0.017 \\
\mathrm{p}=0.284\end{array}$ & $\begin{array}{c}-0.011 \\
\mathrm{p}=0.518\end{array}$ & $\begin{array}{c}-0.093^{* * *} \\
\mathrm{p}=0.0002\end{array}$ & $\begin{array}{c}-0.066 \\
\mathrm{p}=0.484\end{array}$ & $\begin{array}{c}-0.716^{* * *} \\
\mathrm{p}=0.00002\end{array}$ \\
\hline Loss aversion & $\begin{array}{c}0.007 \\
\mathrm{p}=0.576\end{array}$ & $\begin{array}{c}0.009 \\
\mathrm{p}=0.517\end{array}$ & $\begin{array}{c}0.032^{*} \\
\mathrm{p}=0.096\end{array}$ & $\begin{array}{c}0.044 \\
\mathrm{p}=0.569\end{array}$ & $\begin{array}{c}0.278^{* *} \\
\mathrm{p}=0.047\end{array}$ \\
\hline Single supplier group : cognitive effort & & & $\begin{array}{c}-0.034 \\
\mathrm{p}=0.460\end{array}$ & & $\begin{array}{c}-0.449 \\
\mathrm{p}=0.116\end{array}$ \\
\hline Single supplier group: Implied endorsement & & & $\begin{array}{c}0.159^{* * *} \\
\mathrm{p}=0.00001\end{array}$ & & $\begin{array}{c}1.001^{* * *} \\
\mathrm{p}=0.00000\end{array}$ \\
\hline Single supplier group: Loss aversion & & & $\begin{array}{c}-0.043^{*} \\
\mathrm{p}=0.097\end{array}$ & & $\begin{array}{c}-0.339^{* *} \\
\mathrm{p}=0.040\end{array}$ \\
\hline Male & & $\begin{array}{c}-0.001 \\
\mathrm{p}=0.984\end{array}$ & $\begin{array}{c}0.005 \\
\mathrm{p}=0.868\end{array}$ & $\begin{array}{c}-0.004 \\
\mathrm{p}=0.983\end{array}$ & $\begin{array}{c}0.032 \\
\mathrm{p}=0.867\end{array}$ \\
\hline Age & & $\begin{array}{c}-0.008 \\
\mathrm{p}=0.467\end{array}$ & $\begin{array}{c}-0.011 \\
\mathrm{p}=0.346\end{array}$ & $\begin{array}{c}-0.036 \\
\mathrm{p}=0.562\end{array}$ & $\begin{array}{c}-0.042 \\
\mathrm{p}=0.524\end{array}$ \\
\hline Education: secondary & & $\begin{array}{c}0.051 \\
\mathrm{p}=0.602\end{array}$ & $\begin{array}{c}0.084 \\
\mathrm{p}=0.384\end{array}$ & $\begin{array}{c}0.166 \\
\mathrm{p}=0.764\end{array}$ & $\begin{array}{c}0.354 \\
\mathrm{p}=0.538\end{array}$ \\
\hline Education: Degree or higher & & $\begin{array}{c}0.033 \\
\mathrm{p}=0.734\end{array}$ & $\begin{array}{c}0.059 \\
\mathrm{p}=0.546\end{array}$ & $\begin{array}{c}0.064 \\
\mathrm{p}=0.909\end{array}$ & $\begin{array}{c}0.202 \\
\mathrm{p}=0.726\end{array}$ \\
\hline Private rent & & $\begin{array}{c}-0.049 \\
\mathrm{p}=0.296\end{array}$ & $\begin{array}{c}-0.056 \\
\mathrm{p}=0.225\end{array}$ & $\begin{array}{c}-0.338 \\
\mathrm{p}=0.206\end{array}$ & $\begin{array}{c}-0.412 \\
\mathrm{p}=0.137\end{array}$ \\
\hline Rent free & & $\begin{array}{c}-0.022 \\
\mathrm{p}=0.836\end{array}$ & $\begin{array}{c}-0.043 \\
\mathrm{p}=0.679\end{array}$ & $\begin{array}{c}-0.052 \\
\mathrm{p}=0.929\end{array}$ & $\begin{array}{c}-0.137 \\
\mathrm{p}=0.811\end{array}$ \\
\hline Social rent & & $\begin{array}{c}-0.025 \\
\mathrm{p}=0.566\end{array}$ & $\begin{array}{c}-0.026 \\
\mathrm{p}=0.553\end{array}$ & $\begin{array}{c}-0.138 \\
\mathrm{p}=0.573\end{array}$ & $\begin{array}{c}-0.136 \\
\mathrm{p}=0.589\end{array}$ \\
\hline Moved & & $\begin{array}{c}0.090 \\
\mathrm{p}=0.169\end{array}$ & $\begin{array}{c}0.092 \\
\mathrm{p}=0.155\end{array}$ & $\begin{array}{c}0.614^{*} \\
\mathrm{p}=0.092\end{array}$ & $\begin{array}{c}0.705^{*} \\
\mathrm{p}=0.069\end{array}$ \\
\hline Satisfaction with current energy supplier & & $\begin{array}{c}0.010 \\
\mathrm{p}=0.536\end{array}$ & $\begin{array}{c}0.016 \\
\mathrm{p}=0.309\end{array}$ & $\begin{array}{c}0.067 \\
\mathrm{p}=0.453\end{array}$ & $\begin{array}{c}0.115 \\
\mathrm{p}=0.204\end{array}$ \\
\hline Don't know if switched tariff/supplier & & $\begin{array}{c}0.085^{*} \\
\mathrm{p}=0.095\end{array}$ & $\begin{array}{c}0.094^{*} \\
\mathrm{p}=0.061\end{array}$ & $\begin{array}{c}0.437 \\
\mathrm{p}=0.118\end{array}$ & $\begin{array}{c}0.522^{*} \\
\mathrm{p}=0.071\end{array}$ \\
\hline Switched tariff/supplier more than 12 months ago & & $\begin{array}{c}0.059 \\
\mathrm{p}=0.114\end{array}$ & $\begin{array}{c}0.061^{*} \\
\mathrm{p}=0.096\end{array}$ & $\begin{array}{c}0.318 \\
\mathrm{p}=0.124\end{array}$ & $\begin{array}{c}0.344 \\
\mathrm{p}=0.107\end{array}$ \\
\hline Switched tariff/supplier within 12 months & & $\begin{array}{c}0.013 \\
\mathrm{p}=0.862\end{array}$ & $\begin{array}{c}0.011 \\
\mathrm{p}=0.883\end{array}$ & $\begin{array}{c}-0.034 \\
\mathrm{p}=0.939\end{array}$ & $\begin{array}{c}-0.013 \\
\mathrm{p}=0.978\end{array}$ \\
\hline Switched tariff/supplier within 3 months & & $\begin{array}{c}-0.194 \\
\mathrm{p}=0.253\end{array}$ & $\begin{array}{c}-0.277^{*} \\
\mathrm{p}=0.099\end{array}$ & $\begin{array}{c}-1.565 \\
\mathrm{p}=0.201\end{array}$ & $\begin{array}{c}-2.252^{*} \\
\mathrm{p}=0.074\end{array}$ \\
\hline Income $£ 21,001-£ 41,000$ & & $\begin{array}{c}0.020 \\
\mathrm{p}=0.576\end{array}$ & $\begin{array}{c}0.016 \\
\mathrm{p}=0.656\end{array}$ & $\begin{array}{c}0.109 \\
\mathrm{p}=0.594\end{array}$ & $\begin{array}{c}0.130 \\
\mathrm{p}=0.533\end{array}$ \\
\hline Income $£ 41,001+$ & & $\begin{array}{c}-0.075 \\
\mathrm{p}=0.172\end{array}$ & $\begin{array}{c}-0.068 \\
\mathrm{p}=0.208\end{array}$ & $\begin{array}{c}-0.446 \\
\mathrm{p}=0.148\end{array}$ & $\begin{array}{c}-0.421 \\
\mathrm{p}=0.179\end{array}$ \\
\hline Regional fixed effects & & & & $\checkmark$ & $\checkmark$ \\
\hline $\begin{array}{l}\text { Observations } \\
\mathrm{R}^{2} \\
\text { Adjusted } \mathrm{R}^{2}\end{array}$ & $\begin{array}{l}776 \\
0.211 \\
0.207\end{array}$ & $\begin{array}{c}714 \\
0.230 \\
0.209\end{array}$ & $\begin{array}{l}714 \\
0.258 \\
0.235\end{array}$ & 714 & 714 \\
\hline Log Likelihood & & & & -379.900 & -363.744 \\
\hline Akaike Inf. Crit. & & & & 819.801 & 793.487 \\
\hline Residual Std. Error & $0.431(\mathrm{df}=771)$ & $0.431(\mathrm{df}=694)$ & $0.424(\mathrm{df}=691)$ & & \\
\hline F Statistic & $51.422^{* * *}(\mathrm{df}=4 ; 771)$ & $10.928^{* * *}(\mathrm{df}=19 ; 694)$ & $10.940^{* * *}(\mathrm{df}=22 ; 691)$ & & \\
\hline
\end{tabular}


Table 9: OLS Regression Models and regional fixed effects - experiment 2 (consumer preferences

\begin{tabular}{|c|c|c|c|c|}
\hline & \multicolumn{4}{|c|}{ Dependent variable: } \\
\hline & \multicolumn{4}{|c|}{ Switching to/adding Local energy supplier } \\
\hline & \multicolumn{2}{|c|}{ OLS regression models } & \multicolumn{2}{|c|}{ Logistic regression models with regional fixed effects } \\
\hline & (1) & $(2)$ & (3) & $(4)$ \\
\hline \multirow[t]{2}{*}{ Multiple supplier condition } & $0.104^{* * *}$ & 0.054 & $0.447^{* * *}$ & 0.254 \\
\hline & $\mathrm{p}=0.007$ & $\mathrm{p}=0.559$ & $\mathrm{p}=0.008$ & $\mathrm{p}=0.528$ \\
\hline \multirow{2}{*}{ Loss aversion } & -0.007 & -0.016 & -0.026 & -0.060 \\
\hline & $\mathrm{p}=0.638$ & $\mathrm{p}=0.453$ & $\mathrm{p}=0.711$ & $\mathrm{p}=0.527$ \\
\hline \multirow[t]{2}{*}{ Multiple supplier condition: loss aversion } & & 0.018 & & 0.071 \\
\hline & & $\mathrm{p}=0.549$ & & $\mathrm{p}=0.597$ \\
\hline \multirow[t]{2}{*}{$\overline{\overline{\text { Cognitive effort }}}$} & 0.024 & 0.024 & 0.078 & 0.080 \\
\hline & $\mathrm{p}=0.428$ & $\mathrm{p}=0.425$ & $\mathrm{p}=0.562$ & $\mathrm{p}=0.552$ \\
\hline \multirow[t]{2}{*}{ Male } & -0.032 & -0.033 & -0.158 & -0.160 \\
\hline & $\mathrm{p}=0.404$ & $\mathrm{p}=0.397$ & $\mathrm{p}=0.354$ & $\mathrm{p}=0.347$ \\
\hline \multirow[t]{2}{*}{ Age } & -0.006 & -0.006 & -0.023 & -0.023 \\
\hline & $\mathrm{p}=0.665$ & $\mathrm{p}=0.658$ & $\mathrm{p}=0.710$ & $\mathrm{p}=0.704$ \\
\hline \multirow[t]{2}{*}{ Education: secondary } & -0.112 & -0.113 & -0.584 & -0.585 \\
\hline & $\mathrm{p}=0.303$ & $\mathrm{p}=0.301$ & $\mathrm{p}=0.224$ & $\mathrm{p}=0.222$ \\
\hline \multirow[t]{2}{*}{ Education: degree or higher } & -0.021 & -0.023 & -0.239 & -0.244 \\
\hline & $\mathrm{p}=0.848$ & $\mathrm{p}=0.837$ & $\mathrm{p}=0.622$ & $\mathrm{p}=0.615$ \\
\hline \multirow[t]{2}{*}{ Private rent } & $0.147^{* * *}$ & $0.149^{* * * *}$ & $0.608^{* *}$ & $0.615^{* *}$ \\
\hline & $\mathrm{p}=0.009$ & $\mathrm{p}=0.008$ & $\mathrm{p}=0.012$ & $\mathrm{p}=0.012$ \\
\hline \multirow[t]{2}{*}{ Rent free } & 0.195 & 0.197 & 0.825 & 0.833 \\
\hline & $\mathrm{p}=0.161$ & $\mathrm{p}=0.157$ & $\mathrm{p}=0.177$ & $\mathrm{p}=0.173$ \\
\hline \multirow[t]{2}{*}{ Social rent } & -0.015 & -0.016 & -0.071 & -0.071 \\
\hline & $\mathrm{p}=0.773$ & $\mathrm{p}=0.770$ & $\mathrm{p}=0.765$ & $\mathrm{p}=0.767$ \\
\hline \multirow[t]{2}{*}{ Moved house within last 12 months } & -0.015 & -0.015 & -0.066 & -0.069 \\
\hline & $\mathrm{p}=0.837$ & $\mathrm{p}=0.830$ & $\mathrm{p}=0.832$ & $\mathrm{p}=0.825$ \\
\hline \multirow[t]{2}{*}{ Satisfaction with current energy supplier } & $-0.035^{*}$ & $-0.035^{*}$ & $-0.161^{* *}$ & $-0.160^{* *}$ \\
\hline & $\mathrm{p}=0.055$ & $\mathrm{p}=0.056$ & $\mathrm{p}=0.047$ & $\mathrm{p}=0.048$ \\
\hline \multirow[t]{2}{*}{ Don't know if switched tariff/supplier } & 0.031 & 0.029 & 0.110 & 0.103 \\
\hline & $\mathrm{p}=0.623$ & $\mathrm{p}=0.646$ & $\mathrm{p}=0.685$ & $\mathrm{p}=0.707$ \\
\hline \multirow[t]{2}{*}{ Switched tariff/supplier more than 12 months ago } & $0.071^{*}$ & 0.069 & $0.332^{*}$ & $0.323^{*}$ \\
\hline & $\mathrm{p}=0.098$ & $\mathrm{p}=0.110$ & $\mathrm{p}=0.078$ & $\mathrm{p}=0.087$ \\
\hline \multirow[t]{2}{*}{ Switched tariff/supplier within last 12 months } & 0.055 & 0.057 & 0.238 & 0.246 \\
\hline & $\mathrm{p}=0.574$ & $\mathrm{p}=0.564$ & $\mathrm{p}=0.576$ & $\mathrm{p}=0.564$ \\
\hline \multirow[t]{2}{*}{ Switched tariff/supplier within last 3 months } & $-0.288^{* *}$ & $-0.291^{* *}$ & $-1.927^{*}$ & $-1.930^{*}$ \\
\hline & $\mathrm{p}=0.049$ & $\mathrm{p}=0.047$ & $\mathrm{p}=0.071$ & $\mathrm{p}=0.070$ \\
\hline \multirow[t]{2}{*}{ Income $£ 21,001-£ 41,000$} & 0.018 & 0.016 & 0.082 & 0.074 \\
\hline & $\mathrm{p}=0.657$ & $\mathrm{p}=0.693$ & $\mathrm{p}=0.649$ & $\mathrm{p}=0.684$ \\
\hline Income $£ 41,001+$ & 0.085 & 0.088 & 0.347 & 0.360 \\
\hline & $\mathrm{p}=0.219$ & $\mathrm{p}=0.203$ & $\mathrm{p}=0.249$ & $\mathrm{p}=0.234$ \\
\hline Regional fixed effects & & & $\checkmark$ & $\checkmark$ \\
\hline Observations & 664 & 664 & 664 & 664 \\
\hline $\mathrm{R}^{2}$ & 0.061 & 0.062 & & \\
\hline Adjusted $\mathrm{R}^{2}$ & 0.035 & 0.034 & & \\
\hline Log Likelihood & & & -425.285 & -425.145 \\
\hline Akaike Inf. Crit. & & & 908.571 & 910.291 \\
\hline Residual Std. Error & $0.485(\mathrm{df}=645)$ & $0.485(\mathrm{df}=644)$ & & \\
\hline F Statistic & $2.332^{* * *}(\mathrm{df}=18 ; 645)$ & $2.226^{* * *}(\mathrm{df}=19 ; 644)$ & & \\
\hline
\end{tabular}




\section{Exclusion criteria - no exclusion criteria applied}

Table 10: Results of logistic regression models with no exclusion criteria applied - experiment 1 (default mechanisms)

- Dependent variable:

Switching away from default

\begin{tabular}{|c|c|c|c|}
\hline & $(1)$ & $(2)$ & $(3)$ \\
\hline Single supplier group & $\begin{array}{c}1.956^{* * *} \\
\mathrm{p}=0.000\end{array}$ & $\begin{array}{c}2.031^{* * *} \\
\mathrm{p}=0.000\end{array}$ & $\begin{array}{c}0.852 \\
\mathrm{p}=0.492\end{array}$ \\
\hline Cognitive effort & $\begin{array}{c}0.232^{* *} \\
\mathrm{p}=0.047\end{array}$ & $\begin{array}{c}0.252^{* *} \\
\mathrm{p}=0.047\end{array}$ & $\begin{array}{c}0.419^{* *} \\
\mathrm{p}=0.043\end{array}$ \\
\hline Implied endorsement & $\begin{array}{c}-0.058 \\
\mathrm{p}=0.489\end{array}$ & $\begin{array}{c}-0.029 \\
\mathrm{p}=0.745\end{array}$ & $\begin{array}{l}-0.604^{* * *} \\
\mathrm{p}=0.0001\end{array}$ \\
\hline Loss-aversion & $\begin{array}{c}0.064 \\
p=0.318\end{array}$ & $\begin{array}{c}0.056 \\
p=0.432\end{array}$ & $\begin{array}{c}0.271^{* *} \\
\mathrm{p}=0.041\end{array}$ \\
\hline Single supplier group:cognitive effort & & & $\begin{array}{c}-0.225 \\
\mathrm{p}=0.389\end{array}$ \\
\hline Single supplier group: implied endorsement & & & $\begin{array}{c}0.887^{* * *} \\
\mathrm{p}=0.00001\end{array}$ \\
\hline Single supplier group: loss-aversion & & & $\begin{array}{c}-0.317^{* *} \\
\mathrm{p}=0.043\end{array}$ \\
\hline Male & & $\begin{array}{c}-0.076 \\
\mathrm{p}=0.662\end{array}$ & $\begin{array}{c}-0.047 \\
p=0.790\end{array}$ \\
\hline Age & & $\begin{array}{c}0.018 \\
\mathrm{p}=0.762\end{array}$ & $\begin{array}{c}0.012 \\
\mathrm{p}=0.840\end{array}$ \\
\hline Education: secondary school & & $\begin{array}{c}-0.005 \\
\mathrm{p}=0.991\end{array}$ & $\begin{array}{c}0.202 \\
\mathrm{p}=0.684\end{array}$ \\
\hline Education: degree or higher & & $\begin{array}{c}-0.092 \\
\mathrm{p}=0.850\end{array}$ & $\begin{array}{c}0.092 \\
p=0.854\end{array}$ \\
\hline Private renter & & $\begin{array}{c}-0.265 \\
\mathrm{p}=0.290\end{array}$ & $\begin{array}{c}-0.299 \\
\mathrm{p}=0.244\end{array}$ \\
\hline Rent free & & $\begin{array}{c}-0.111 \\
\mathrm{p}=0.840\end{array}$ & $\begin{array}{c}-0.205 \\
\mathrm{p}=0.706\end{array}$ \\
\hline Social renter & & $\begin{array}{c}-0.148 \\
\mathrm{p}=0.517\end{array}$ & $\begin{array}{c}-0.163 \\
\mathrm{p}=0.483\end{array}$ \\
\hline Moved house within last 12 months & & $\begin{array}{c}0.578^{*} \\
\mathrm{p}=0.092\end{array}$ & $\begin{array}{c}0.643^{*} \\
\mathrm{p}=0.074\end{array}$ \\
\hline Satisfaction with energy supplier & & $\begin{array}{c}0.009 \\
\mathrm{p}=0.917\end{array}$ & $\begin{array}{c}0.053 \\
\mathrm{p}=0.530\end{array}$ \\
\hline Don't know if switched tariff/supplier & & $\begin{array}{c}0.538^{* *} \\
\mathrm{p}=0.042\end{array}$ & $\begin{array}{c}0.618^{* *} \\
\mathrm{p}=0.023\end{array}$ \\
\hline Switched tariff/supplier more than 12 months ago & & $\begin{array}{c}0.356^{*} \\
\mathrm{p}=0.068\end{array}$ & $\begin{array}{c}0.370^{*} \\
\mathrm{p}=0.063\end{array}$ \\
\hline Switched tariff/supplier within last 12 months & & $\begin{array}{c}-0.179 \\
\mathrm{p}=0.663\end{array}$ & $\begin{array}{c}-0.197 \\
\mathrm{p}=0.636\end{array}$ \\
\hline Switched tariff/supplier more than 12 months ago & & $\begin{array}{c}-1.476 \\
\mathrm{p}=0.212\end{array}$ & $\begin{array}{c}-2.009^{*} \\
\mathrm{p}=0.100\end{array}$ \\
\hline Income: $£ 21,001-£ 41,000$ & & $\begin{array}{c}0.154 \\
\mathrm{p}=0.417\end{array}$ & $\begin{array}{c}0.147 \\
\mathrm{p}=0.447\end{array}$ \\
\hline Income: $£ 41,001+$ & & $\begin{array}{c}-0.246 \\
\mathrm{p}=0.399\end{array}$ & $\begin{array}{c}-0.236 \\
\mathrm{p}=0.425\end{array}$ \\
\hline Observations & 838 & 768 & 768 \\
\hline Log Likelihood & -463.280 & -415.152 & -401.532 \\
\hline Akaike Inf. Crit. & 936.560 & 870.304 & 849.065 \\
\hline
\end{tabular}

Note:

${ }^{*} \mathrm{p}<0.1 ;{ }^{* *} \mathrm{p}<0.05 ;{ }^{* * *} \mathrm{p}<0.01$ 
Table 11: Results of logistic regression models with no exclusion criteria applied - experiment 2 (consumer preferences)

$\overline{\text { Dependent variable: }}$

Switching to/adding Local energy supplier

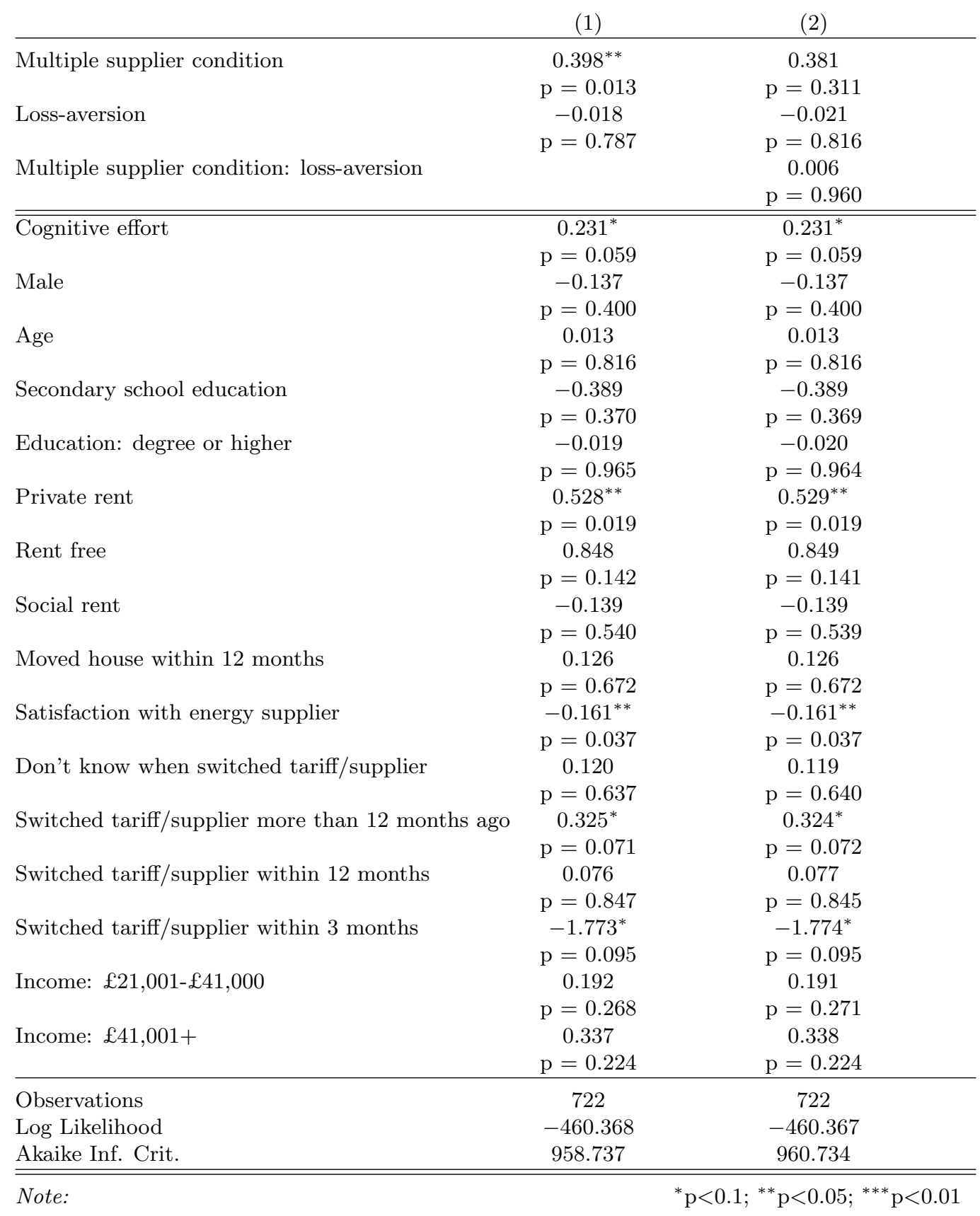


Benjamini Hochberg correction for multiple hypotheses (default mechanisms experiment only - model with all covariates and interaction effects)

\begin{tabular}{|c|c|}
\hline & Dependent variable: \\
\hline & Switched away from default \\
\hline Single supplier group & $\begin{array}{c}1.388 \\
\mathrm{p}=0.440\end{array}$ \\
\hline Cognitive effort & $\begin{array}{c}0.565^{*} \\
\mathrm{p}=0.077\end{array}$ \\
\hline Implied endorsement & $\begin{array}{l}-0.700^{* * *} \\
\mathrm{p}=0.0003\end{array}$ \\
\hline Loss aversion & $\begin{array}{c}0.268 \\
\mathrm{p}=0.192\end{array}$ \\
\hline Single supplier group: cognitive effort & $\begin{array}{c}-0.425 \\
\mathrm{p}=0.263\end{array}$ \\
\hline Single supplier group: implied endorsement & $\begin{array}{c}0.993^{* * *} \\
\mathrm{p}=0.00002\end{array}$ \\
\hline Single supplier group: loss aversion & $\begin{array}{c}-0.330 \\
\mathrm{p}=0.192\end{array}$ \\
\hline Male & $\begin{array}{c}0.038 \\
\mathrm{p}=0.876\end{array}$ \\
\hline Age & $\begin{array}{c}-0.045 \\
\mathrm{p}=0.659\end{array}$ \\
\hline Education: secondary school & $\begin{array}{c}0.417 \\
\mathrm{p}=0.659\end{array}$ \\
\hline Education: degree or higher & $\begin{array}{c}0.273 \\
\mathrm{p}=0.723\end{array}$ \\
\hline Private rent & $\begin{array}{c}-0.305 \\
\mathrm{p}=0.421\end{array}$ \\
\hline Rent free & $\begin{array}{c}-0.170 \\
\mathrm{p}=0.836\end{array}$ \\
\hline Social rent & $\begin{array}{c}-0.130 \\
\mathrm{p}=0.723\end{array}$ \\
\hline Moved house within last 12 months & $\begin{array}{c}0.630 \\
\mathrm{p}=0.243\end{array}$ \\
\hline Satisfaction with energy supplier & $\begin{array}{c}0.106 \\
\mathrm{p}=0.408\end{array}$ \\
\hline Don't know if switched tariff/supplier & $\begin{array}{c}0.532 \\
\mathrm{p}=0.204\end{array}$ \\
\hline Switched tariff/supplier more than 12 months ago & $\begin{array}{c}0.328 \\
\mathrm{p}=0.263\end{array}$ \\
\hline Switched tariff/supplier within last 12 months & $\begin{array}{c}0.044 \\
\mathrm{p}=0.922\end{array}$ \\
\hline Switched tariff/supplier within last 3 months & $\begin{array}{c}-2.206 \\
\mathrm{p}=0.235\end{array}$ \\
\hline Income: £21,001-£41,000 & $\begin{array}{c}0.120 \\
\mathrm{p}=0.710\end{array}$ \\
\hline Income: $£ 41,001+$ & $\begin{array}{c}-0.404 \\
\mathrm{p}=0.363\end{array}$ \\
\hline Observations & 714 \\
\hline Log Likelihood & -368.747 \\
\hline Akaike Inf. Crit. & 783.493 \\
\hline
\end{tabular}

Note: 
Table 13: Logistic regression coefficients with alternative specification of loss-aversion - experiment 1 (default mechanisms)

- Dependent variable:

Switching away from default

\begin{tabular}{|c|c|c|c|}
\hline & $(1)$ & $(2)$ & $(3)$ \\
\hline Single supplier group & $\begin{array}{c}2.047^{* * *} \\
\mathrm{p}=0.000\end{array}$ & $\begin{array}{l}2.107^{* * *} \\
\mathrm{p}=0.000\end{array}$ & $\begin{array}{c}1.485 \\
\mathrm{p}=0.283\end{array}$ \\
\hline Cognitive effort & $\begin{array}{c}0.220^{*} \\
\mathrm{p}=0.070\end{array}$ & $\begin{array}{c}0.274^{* *} \\
\mathrm{p}=0.039\end{array}$ & $\begin{array}{c}0.548^{* *} \\
\mathrm{p}=0.012\end{array}$ \\
\hline Implied endorsement & $\begin{array}{c}-0.093 \\
\mathrm{p}=0.290\end{array}$ & $\begin{array}{c}-0.052 \\
\mathrm{p}=0.577\end{array}$ & $\begin{array}{c}-0.715^{* * *} \\
\mathrm{p}=0.00002\end{array}$ \\
\hline Loss-aversion & $\begin{array}{c}-0.004 \\
\mathrm{p}=0.989\end{array}$ & $\begin{array}{c}-0.190 \\
\mathrm{p}=0.560\end{array}$ & $\begin{array}{c}0.671 \\
\mathrm{p}=0.321\end{array}$ \\
\hline Single supplier group:cognitive effort & & & $\begin{array}{c}-0.410 \\
\mathrm{p}=0.136\end{array}$ \\
\hline Single supplier group: implied endorsement & & & $\begin{array}{c}1.022^{* * *} \\
\mathrm{p}=0.00000\end{array}$ \\
\hline Single supplier group: loss-aversion & & & $\begin{array}{c}-1.281 \\
\mathrm{p}=0.107\end{array}$ \\
\hline Male & & $\begin{array}{c}-0.018 \\
\mathrm{p}=0.924\end{array}$ & $\begin{array}{c}0.012 \\
\mathrm{p}=0.951\end{array}$ \\
\hline Age & & $\begin{array}{c}-0.029 \\
\mathrm{p}=0.633\end{array}$ & $\begin{array}{c}-0.034 \\
\mathrm{p}=0.587\end{array}$ \\
\hline Education: secondary school & & $\begin{array}{c}0.270 \\
\mathrm{p}=0.619\end{array}$ & $\begin{array}{c}0.473 \\
\mathrm{p}=0.403\end{array}$ \\
\hline Education: degree or higher & & $\begin{array}{c}0.162 \\
\mathrm{p}=0.767\end{array}$ & $\begin{array}{c}0.332 \\
\mathrm{p}=0.558\end{array}$ \\
\hline Private renter & & $\begin{array}{c}-0.269 \\
\mathrm{p}=0.301\end{array}$ & $\begin{array}{c}-0.336 \\
\mathrm{p}=0.213\end{array}$ \\
\hline Rent free & & $\begin{array}{c}0.011 \\
\mathrm{p}=0.985\end{array}$ & $\begin{array}{c}-0.094 \\
\mathrm{p}=0.868\end{array}$ \\
\hline Social renter & & $\begin{array}{c}-0.122 \\
\mathrm{p}=0.614\end{array}$ & $\begin{array}{c}-0.095 \\
\mathrm{p}=0.701\end{array}$ \\
\hline Moved house within last 12 months & & $\begin{array}{c}0.562 \\
\mathrm{p}=0.114\end{array}$ & $\begin{array}{c}0.657^{*} \\
\mathrm{p}=0.079\end{array}$ \\
\hline Satisfaction with energy supplier & & $\begin{array}{c}0.054 \\
\mathrm{p}=0.532\end{array}$ & $\begin{array}{c}0.100 \\
\mathrm{p}=0.264\end{array}$ \\
\hline Don't know if switched tariff/supplier & & $\begin{array}{c}0.442 \\
\mathrm{p}=0.108\end{array}$ & $\begin{array}{c}0.529^{*} \\
\mathrm{p}=0.063\end{array}$ \\
\hline Switched tariff/supplier more than 12 months ago & & $\begin{array}{c}0.308 \\
\mathrm{p}=0.129\end{array}$ & $\begin{array}{c}0.336 \\
\mathrm{p}=0.106\end{array}$ \\
\hline Switched tariff/supplier within last 12 months & & $\begin{array}{c}0.040 \\
\mathrm{p}=0.927\end{array}$ & $\begin{array}{c}0.052 \\
\mathrm{p}=0.907\end{array}$ \\
\hline Switched tariff/supplier more than 12 months ago & & $\begin{array}{c}-1.657 \\
\mathrm{p}=0.182\end{array}$ & $\begin{array}{c}-2.426^{*} \\
\mathrm{p}=0.068\end{array}$ \\
\hline Income: $£ 21,001-£ 41,000$ & & $\begin{array}{c}0.104 \\
\mathrm{p}=0.600\end{array}$ & $\begin{array}{c}0.113 \\
\mathrm{p}=0.577\end{array}$ \\
\hline Income: $£ 41,001+$ & & $\begin{array}{c}-0.431 \\
\mathrm{p}=0.154\end{array}$ & $\begin{array}{c}-0.417 \\
\mathrm{p}=0.175\end{array}$ \\
\hline Observations & 776 & 714 & 714 \\
\hline Log Likelihood & -426.544 & -385.010 & -369.428 \\
\hline Akaike Inf. Crit. & 863.089 & 810.019 & 784.857 \\
\hline
\end{tabular}

\section{Note:}


Table 14: Logistic regression coefficients with alternative specification of loss-aversion - experiment 2 (consumer preferences)

$\overline{\text { switched }}$

switched

(1)

Multiple supplier condition

$(2)$

Loss aversion

$0.446^{* * *}$

$\mathrm{p}=0.007$

0.202

0.256

$\mathrm{p}=0.712$

$\mathrm{p}=0.385$

0.131

Multiple supplier condition: loss aversion_binary

$\mathrm{p}=0.741$

0.269

$\overline{\text { Cognitive effort }}$

$\mathrm{p}=0.639$

Male

0.096

$\mathrm{p}=0.465$

$-0.123$

$\mathrm{p}=0.476$

$\mathrm{p}=0.460$

$-0.127$

Age

$-0.038$

$\mathrm{p}=0.446$

$\mathrm{p}=0.522$

$-0.038$

Education: secondary school

$-0.500$

$\mathrm{p}=0.516$

$\mathrm{p}=0.285$

$-0.515$

Education: degree or higher

$-0.081$

$\mathrm{p}=0.271$

$\mathrm{p}=0.864$

$-0.099$

Private rent

$0.630^{* * *}$

$\mathrm{p}=0.833$

$\mathrm{p}=0.008$

$0.631^{* * *}$

Rent free

0.827

$\mathrm{p}=0.008$

$\mathrm{p}=0.169$

0.826

Social rent

Moved house within last 12 months

$-0.072$

$\mathrm{p}=0.170$

$\mathrm{p}=0.760$

$-0.070$

$-0.040$

$\mathrm{p}=0.767$

$\mathrm{p}=0.896$

$-0.041$

Satisfaction with energy supplier

$-0.153^{*}$

$\mathrm{p}=0.894$

$\mathrm{p}=0.053$

$-0.152^{*}$

0.123

$\mathrm{p}=0.056$

Don't know if switched tariff/supplier

$\mathrm{p}=0.648$

$0.308^{*}$

0.124

Switched tariff/supplier more than 12 months ago

$\mathrm{p}=0.095$

$\mathrm{p}=0.644$

0.232

Switched tariff/supplier within 12 months

$\mathrm{p}=0.581$

$\mathrm{p}=0.097$

Switched tariff/supplier within 3 months

$-1.871^{*}$

$\mathrm{p}=0.078$

0.083

$\mathrm{p}=0.578$

Income: $£ 21,001-£ 41,000$

$\mathrm{p}=0.642$

$-1.889^{*}$

$\mathrm{p}=0.076$

0.081

Income: $£ 41,001+$

$$
0.371
$$

$\mathrm{p}=0.652$

$\mathrm{p}=0.208$

0.379

Observations

664

Log Likelihood

$-429.255$

$=0.199$

Akaike Inf. Crit.

896.511

664

$-429.146$

898.291

Note:

${ }^{*} \mathrm{p}<0.1 ;{ }^{* *} \mathrm{p}<0.05 ;{ }^{* * *} \mathrm{p}<0.01$ 